\title{
EL CUIDADO PERSONAL DE NIÑOS Y ADOLESCENTES EN LA FAMILIA SEPARADA: CRITERIOS DE RESOLUCIÓN DE CONFLICTOS DE INTERESES ENTRE PADRES E HIJOS EN EL NUEVO DERECHO CHILENO DE FAMILIA*
}

\author{
THE CUSTODY OF CHILDREN AND TEENAGERS IN SEPARATED \\ FAMILIES: LEGAL CRITERIA FOR THE RESOLUTION OF CONFLICTS \\ OF INTEREST BETWEEN PARENTS AND CHILDREN IN THE NEW \\ CHILEAN FAMILY LAW
}

\section{MARÍA SARA RodRÍGUEZ PINTO**}

\begin{abstract}
RESUMEN: Este artículo examina los factores de atribución del cuidado personal de niños, niñas y adolescentes durante la vida separada de sus padres, bajo los criterios del nuevo Derecho chileno de familia. En la primera parte se analizan las convenciones sobre atribución del cuidado personal de los hijos. En la segunda, se examina la regla de atribución supletoria legal a la madre. La autora defiende las ventajas de la existencia de una regla de atribución supletoria y automática del cuidado personal de los hijos en caso de desacuerdo entre los padres. La tercera parte se refiere a los juicios entre progenitores sobre el cuidado personal de sus hijos. En esta parte se analiza el principio del interés superior del niño como criterio de atribución judicial de la tuición entre progenitores y su funcionamiento en juicio. Este criterio ha desplazado los criterios de inhabilidad de la madre (o del padre), los cuales, sin embargo, subsisten como criterios de separación de niños, niñas o adolescentes de sus padres biológicos para entregar su cuidado a terceros, parientes o extraños.
\end{abstract}

Palabras clave: cuidado personal de los hijos; niños, niñas y adolescentes; tuición; menores; interés superior del niño; conflicto de intereses; familia; Derecho de Familia.

ABSTRACT: This paper examines different criteria of adjudication of custody to parents in cases of separation, according to the new Chilean Family Law. In the first part, the author discusses the function of settlements made out of mutual consent between parents and its advantages. The second part of this study discusses the advantages of a rule of automatic adjudication of custody, in cases of disagreement between parents. The third part of the article discusses the principle of the best interest of the child as a judicial device to adjudicate cases of custody. The author defends a development in Chilean Law to replace inability with the best interest standard to adjudicate custody between parents. Inability remains as a standard to separate children from their biological parents.

Key words: custody; children and teens; minors; best interest of the child; conflicts of interest; Family; Family Law.

\footnotetext{
* Este trabajo ha sido realizado en el marco del Proyecto Fondecyt $\mathrm{N}^{\circ} 1070077$ sobre los conflictos de intereses en las relaciones paterno-filiales del que la autora ha sido investigadora responsable.

** Licenciada en Derecho por la Pontificia Universidad Católica de Chile, Master of Laws por Northwestern University, Doctora en Derecho por la Universidad Autónoma de Madrid, Profesora de Derecho Civil Universidad de los Andes. Dirección postal: Avenida San Carlos de Apoquindo 2200, Las Condes, Santiago, Chile. Correo electrónico: msr@uandes.cl
} 


\section{INTRODUCCIÓN}

El objetivo de este trabajo es examinar los conflictos de intereses entre padres separados e hijos en el ámbito del cuidado personal o tuición de niños, niñas y adolescentes; y los criterios que ofrece el nuevo Derecho chileno de familia para resolverlos ${ }^{1}$. En el contexto de una familia funcional, las reglas de atribución que ofrece el Derecho pueden resumirse en lo que se explica a continuación. El cuidado personal de los hijos está atribuido por ley a ambos padres de consuno (artículo 224, inciso $1^{\circ}$ del Código Civil $^{2}$ ). Si el matrimonio de los padres ha terminado por muerte, al padre o madre sobreviviente se atribuye legalmente el cuidado personal de sus hijos (artículo 224, inciso $1^{\circ}$ ). Modificando la legislación anterior, la Ley 19.585, de 1998, extiende esta regla legal de atribución al padre o madre que hubiere reconocido al hijo no concebido ni nacido en el matrimonio de sus padres (artículo 224, inciso $2^{\circ}$ ). Es decir, el cuidado personal de hijos no matrimoniales lo tiene el padre o la madre que lo ha reconocido; y ambos de consuno, si viven juntos ${ }^{3}$.

El esquema que proponen estas tres reglas responde al deber y derecho de ambos padres, padre y madre de consuno, de criar y educar a sus hijos y acompañarlos en su desarrollo hasta la madurez, derecho y deber que se encuentra garantizado por el Derecho chileno a todo nivel (artículos $1^{\circ}$ y 19 número $10^{\circ}$ de la Constitución Política; artículos 222, inciso $2^{\circ}$ y 224). Obedece también a la constatación de la doble función, paternidad y maternidad, que ejercitan los progenitores conjuntamente en la crianza y educación de sus hijos; función que es un deber de los padres y un derecho de los hijos; y que se encuentra garantizada con la vida en común de los padres con los hijos y, más aún, con la estabilidad que garantiza a todos los miembros de la familia el matrimonio de los padres. No en vano, reproduciendo el mandato constitucional (artículo $1^{\mathrm{o}}$ de la Constitución Política), la Ley 19.947, de 2004, sobre matrimonio civil (en adelante, LMC), declara como punto de partida que la familia es el núcleo fundamental de la sociedad; y que el matrimonio es la base principal de la familia (artículo 1º, LMC).

Los deberes y derechos de la paternidad y de la maternidad son tan fuertes que autores recientes están calificándolos de indisolubles ${ }^{4}$. Cuando los padres ya no viven junto a sus hijos (por separación, divorcio o nulidad), la indisolubilidad de la paternidad y de la maternidad exige medidas cuidadosas que garanticen, en la medida de lo posible,

\footnotetext{
${ }^{1}$ Veo necesarias dos prevenciones terminológicas. Utilizo indistintamente los términos cuidado personal o tuición. Este último término es reconocido en la legislación vigente sobre menores y sigue en uso en la práctica de los tribunales. Asimismo, empleo a veces la expresión "visitas", hoy erradicada del Código Civil y de la legislación de menores, como equivalente al derecho-deber de mantener con el hijo una relación directa y regular, porque el concepto sigue siendo utilizado en la legislación comparada y en la práctica forense.

${ }^{2}$ En adelante, todas las citas de normas legales que no indiquen su fuente se refieren al Código Civil chileno.

${ }^{3}$ En la legislación vigente anteriormente, los hijos no matrimoniales no estaban sujetos por ley a la tuición y patria potestad del padre o madre que los había reconocido. El juez debía dar un tutor a estos hijos y quedaban sujetos a guarda.

${ }^{4}$ Por ejemplo, PARKINSON (2007) pp. 237-280.
} 
el derecho de los hijos a contar con los cuidados de ambos progenitores. El interés de niños, niñas y adolescentes exige también que se garantice la máxima estabilidad y continuidad en su crianza y educación. Sin embargo, estos deberes deben continuar cumpliéndose en un contexto de crisis familiar, fracaso y, frecuentemente, graves desavenencias que han llevado a los padres a interrumpir o terminar la vida en común junto a sus hijos. El Derecho debe, entonces, arbitrar técnicas que, en la medida de lo posible, garanticen a los niños, niñas y adolescentes involucrados involuntariamente en estas crisis la continuidad de su crianza y educación y la estabilidad de vida que requieren para el desarrollo armónico de su personalidad hasta la madurez. A esto deberían apuntar y este es verdaderamente el objetivo de las reglas de atribución del cuidado personal de los hijos en el supuesto de familias separadas.

Luego de la reforma de la Ley 19.585 de 1998, el Código Civil chileno admite tres mecanismos de atribución de la tuición o cuidado personal de los hijos en supuestos de crisis familiares ${ }^{5}$. El primero es la convención entre el padre y la madre, vehículo que introduce un mayor margen de actividad a la autonomía de la voluntad que el que existía en la legislación anterior y evita la prematura intervención judicial en el conflicto. La convención es el factor privilegiado por la actual legislación y el más beneficioso de todos. El segundo es la ley, que subsiste como criterio de atribución supletorio de la voluntad de los padres, y de funcionamiento automático, sin necesidad de intervención judicial. El recurso al juez de familia es la última opción. Opera si el padre tiene motivos para impugnar la atribución legal a la madre. O bien, si no hay acuerdo entre padre y madre sobre el cuidado personal de sus hijos, o si, habiéndolo, han cambiado las circunstancias que justificaron el acuerdo y los progenitores no consiguen adaptarlo a este nuevo contexto. En todos estos casos toca al juez decidir, a solicitud del padre o de la madre, a cuál de ellos atribuye el cuidado personal de niños, niñas o adolescentes. También toca al juez atribuir la tuición a terceros, parientes o extraños, separando a los hijos del cuidado de sus padres biológicos por inhabilidad física o moral de estos.

En el ámbito judicial, cuando se producen litigios entre progenitores, la regla de autonomía de la voluntad (que favorece los acuerdos entre los padres) o la regla supletoria legal de preferencia materna ceden frente al principio del interés superior del niño. El principio del interés superior del niño, como criterio de adjudicación, tiende a ofrecer mayor espacio de discreción al juzgador para atribuir la tuición al otro de los padres. Pero la intervención judicial exige que las partes produzcan prueba tendiente a integrar un supuesto de hecho: "maltrato, descuido u otra causa calificada" (artículo 225 inciso $3^{\circ}$ ) que justifique un cambio en el cuidado personal del niño. Este trabajo defiende la hipótesis de que el "maltrato, descuido u otra causa calificada" es un supuesto de hecho indeterminado, que el juzgador debe integrar según las reglas de la sana crítica con los medios de prueba producidos legalmente en juicio; y el que el "interés del niño" es criterio indeterminado de adjudicación, que el juez debe también integrar con motivos o

5 Dejaremos fuera de este estudio supuestos en que podrían operar analógicamente esta u otras reglas, como son las medidas de protección de menores, los supuestos de adopción de niños y los casos de responsabilidad penal juvenil. 
razones de experiencia, juicios de valor y argumentos que justifiquen la decisión en función de la finalidad del principio.

Observamos que la inhabilidad de la madre, o del padre, ha dejado de ser criterio preponderante de adjudicación del cuidado personal de los hijos entre progenitores. La inhabilidad de uno o de ambos progenitores subsiste como criterio de adjudicación del cuidado personal a terceros, parientes o extraños (artículo 226), criterio que, al momento de decidir un litigio entre padres y terceros, parientes o extraños, el juez de familia deberá concordar con el principio del interés superior del niño (artículo 242, inciso 20; artículo 16 de la Ley 19.968, sobre Tribunales de Familia; en adelante, LTF).

Las reglas sobre atribución del cuidado personal de niños, niñas y adolescentes tienen, en el Derecho chileno, gran importancia. Quien tiene el cuidado personal de un niño, tiene el deber de criarlo y educarlo. Estos deberes incluyen muchas veces en la práctica decisiones sobre salud, tratamientos médicos, elección del colegio, elección de la religión en que se educa el niño, etcétera. Pero no solo esto; quien tiene el cuidado personal de un niño tiene también la patria potestad (artículo 245 inciso $1^{\circ}$ ). Tiene, por tanto, la representación legal del niño y el derecho de goce y administración de sus bienes.

Conforme a estas líneas de razonamiento, este trabajo se divide en tres partes. En la primera, examinaré la regla de atribución convencional de la tuición, introducida por la Ley 19.585, de 1998: el marco regulatorio e histórico de esta regla y los requisitos de eficacia de los pactos sobre atribución del cuidado personal de los hijos. El estudio comprende el análisis de los problemas de admisibilidad de la atribución convencional a terceros (parientes o extraños), pero no desarrolla la tuición compartida o alternada entre los padres, en el marco de las convenciones posibles entre padre y madre ${ }^{6}$.

En la segunda parte de este trabajo examinaré la regla de atribución supletoria legal de la tuición: sus supuestos, su historia en el Derecho chileno y las ventajas que le atribuye la práctica judicial y la doctrina de los autores. La tercera parte de este trabajo es un estudio de los criterios de atribución judicial del cuidado personal de los hijos, a petición de uno de los padres o de un tercero (pariente o extraño). En esta parte el estudio comprende el análisis de las dos reglas de adjudicación que contempla el Derecho chileno: el principio del interés superior del niño y el criterio de inhabilidad de la madre, del padre o de ambos. Por último, el trabajo se hará cargo de los problemas de atribución judicial de la tuición en supuestos de homosexualidad de uno o de ambos padres.

\section{EL CRITERIO DE ATRIBUCIÓN CONVENCIONAL DE LA TUICIÓN}

\section{A. LA LEY 19.585 Y LA AUTONOMÍA DE LA VOLUNTAD EN LA ATRIBUCIÓN DE LA TUICIÓN}

La Ley 19.585 de 1998 introdujo en la legislación chilena un criterio de atribución preferentemente convencional del cuidado personal de los hijos, entre padre y madre. Este principio quedó plasmado en el artículo 225 inciso $2^{\circ}$, que permite a "ambos padres, actuando de común acuerdo", atribuir el cuidado personal de uno o más

\footnotetext{
${ }^{6}$ Respecto de esta temática: LATHROP (2005); LATHROP (2008); y ROdRÍGUEZ (2008).
} 
hijos al padre. El artículo 229 complementa esta disposición cuando permite acordar, con quien tiene la tuición, la frecuencia y libertad con que el padre o madre que no tiene el cuidado personal del hijo mantendrá su relación con el hijo. Por último, en el artículo 21 de la Ley 19.947 de 2004 sobre matrimonio civil (en adelante, también LMC), se establecen los acuerdos relativos al cuidado de los hijos y al derecho-deber de mantener con ellos una relación directa y regular entre los parámetros básicos de los acuerdos reguladores para el caso de separación, nulidad o divorcio.

Mediante estos acuerdos, los padres pueden determinar que el cuidado personal de uno o más de los hijos corresponda al padre; o pueden acordar -por hipótesis- que el cuidado de los hijos varones pase al padre a partir de determinada edad; o que el cuidado de todos los hijos varones y mujeres, pase al padre. Cabe destacar que la ley solo permite este tipo de convenciones entre los padres. El objeto de estas convenciones siempre consistirá en que el cuidado personal de uno o más de los hijos pase de la madre (que lo tiene por atribución legal o convencional) al padre. Por tanto, a partir de la Ley 19.585, por convención entre los padres pueden separarse los hermanos.

En el marco de un proceso de separación, nulidad o divorcio, las convenciones sobre cuidado personal de los hijos forman parte de los acuerdos reguladores de la vida separada que contempla la Ley 19.947 de 2004 sobre matrimonio civil; y deben incluir un régimen de relación directa y regular con el o los hijos por parte del padre o madre que queda privado de la tuición sobre ellos (artículos 21, 27 y 55 LMC) ${ }^{7}$.

Los pactos sobre atribución convencional de la tuición y regulación del derechodeber a mantener una relación directa y regular con el hijo tienen requisitos de eficacia desde el punto de vista formal y material. Los requisitos de forma son dos: primero, el consentimiento del padre y de la madre; y segundo, el cumplimiento de las formalidades legales. Los requisitos materiales o de fondo se refieren al contenido de estas convenciones. Desde este punto de vista hay pactos admisibles (la regla general) y pactos inadmisibles (las excepciones). Dentro de los pactos admisibles, hay pactos obligatorios y pactos voluntarios. Examinaremos cada uno de estos temas a continuación.

\section{B. REQUISITOS DE FORMA}

\section{Consentimiento del padre y la madre}

Las convenciones celebradas al amparo del artículo 225 inciso $2^{\circ}$ del Código Civil chileno exigen el consentimiento del padre y de la madre: "ambos padres, actuando de común acuerdo...”, se lee en el artículo 225, podrán determinar sobre el cuidado personal de sus hijos. En el marco de un proceso de separación, nulidad o divorcio, los cónyuges (marido y mujer) podrán, "de común acuerdo”, regular sus relaciones mutuas

\footnotetext{
${ }^{7}$ A juicio de este estudio, solo en el marco de estos acuerdos, con aprobación judicial, podrían admitirse de lege ferenda las convenciones sobre cuidado personal compartido o alternado. En estos casos, la regla del artículo 244 (que permite el ejercicio conjunto de la patria potestad por convención) debería prevalecer por sobre el artículo 245 (que radica la patria potestad en quien tiene el cuidado personal del hijo), haciendo la ficción de que no se ha producido la separación, si esto es posible legalmente.
} 
durante la vida separada (artículo 21 de la LMC); y en tal caso deberán regular lo que se refiere al cuidado personal de los hijos y a la relación directa y regular que deberá mantener con ellos aquel de los cónyuges que no los tuviere bajo su cuidado.

Conviene reiterar la importancia de este requisito: estas convenciones exigen el acuerdo de ambos padres. No puede uno de los padres, en quien ha quedado radicado el cuidado personal del o de los hijos por muerte del otro (artículo 224), convenir con un tercero, pariente o extraño, la entrega de la tuición de sus hijos. El cuidado personal de los hijos es una función indelegable. En Tuición del menor Benjamín Cabral May (2004), la Corte de Apelaciones de Santiago resolvió equivocadamente cuando revocó el fallo de primera instancia que denegó la atribución judicial de la tuición a una tía del niño, que pretendía que se declarara que la había obtenido por escritura pública suscrita con el padre. Las partes de esta convención no eran el padre y la madre del menor, sino el padre y una tía materna del niño; y el artículo 225 no permite atribuir el cuidado personal de los hijos por convención con terceros, parientes o extraños ${ }^{8}$.

Cabe cuestionarse si estos acuerdos podrían adoptarse por intermedio de mandatarios o representantes legales. La ley nada dice al respecto y todo indica que se trata de atribuciones personalísimas que no admiten delegación.

\section{Formalidades legales}

El acuerdo de los padres debe hacerse formalmente, mediante escritura pública o acta extendida ante cualquier oficial del Registro Civil (artículo 225 inciso 20). También puede hacerse por escrito sometido a la aprobación del tribunal, en el contexto de un acuerdo regulador de separación de hecho o judicial, nulidad o divorcio (artículos 21, 55 y 67 de la LMC) homologado por una sentencia judicial (artículo 89 de la LMC). Estas formalidades vendrían exigidas por vía de solemnidad ${ }^{9}$. Su incumplimiento estaría sancionado con la nulidad absoluta de los acuerdos.

El acuerdo otorgado por escritura pública o por acta extendida ante un oficial del Registro Civil debe subinscribirse al margen de la inscripción de nacimiento del hijo dentro de los treinta días subsiguientes a su otorgamiento (artículo 225). Respecto de los acuerdos reguladores en el marco de un proceso de separación, nulidad o divorcio, la LMC no exige subinscripción de la sentencia que los homologa; pero, ex analogia del artículo 225, deberían también subinscribirse estas sentencias dentro del plazo de treinta días señalado en el artículo $225^{10}$.

Se ha discutido si estas segundas formalidades están establecidas ad solemnitatem o solamente ad probationem. Si se mantiene su carácter de solemnidades, el incumplimien-

\footnotetext{
${ }^{8}$ El fallo yerra en los fundamentos jurídicos que invoca para atribuir la tuición del niño a su tía, pero no en la atribución misma, que se justifica a todas luces según el contexto y antecedentes del caso por inhabilidad moral del padre (artículo 224 y artículo 226).

${ }^{9}$ AsCENCIO (2000) p. 158; ABELIUK (2000) p. 328; GÓMEZ DE LA TORRE (2007) p. 137.

${ }^{10} \mathrm{La}$ subinscripción de estas convenciones tiene relevancia respecto del efecto que le atribuye el artículo 245: "Si los padres viven separados, la patria potestad será ejercida por aquel que tenga a su cargo el cuidado personal del hijo, de conformidad al artículo 225". La patria potestad corresponde a aquel de los padres que tenga la tuición.
} 
to del plazo o de la subinscripción tiene por efecto la nulidad absoluta e insanable del convenio. Los autores que defienden esta postura se apoyan en la literalidad de la frase

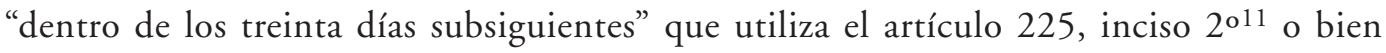
comparan estos acuerdos con los pactos del artículo 1723 del Código Civil y les atribuyen los mismos efectos ${ }^{12}$.

La opinión contraria, que defiende el propósito de publicidad de la subinscripción $^{13}$, tiene algunos argumentos de texto que son importantes. El inciso final del artículo 225 prescribe que "mientras una subinscripción relativa al cuidado personal no sea cancelada por otra posterior, todo nuevo acuerdo o resolución será inoponible a terceros". Luego, el acuerdo es válido entre las partes que concurren a otorgarlo y les es recíprocamente oponible. Lo que sucede es que los terceros que contratan con ellos (aquellos que no conocen las convenciones entre los padres) no están obligados a pasar por ellas.

Esta inoponibilidad podría entonces sanearse subinscribiendo la escritura pública, el acta o la sentencia judicial fuera de plazo, con la finalidad de hacerla oponible a terceros, pues el artículo $6^{\circ}$ de la Ley sobre Registro Civil no exige plazo alguno para subinscribir resoluciones judiciales que disponen sobre el cuidado personal del hijo. A fortiori, no debería exigirlo tampoco para subinscribir escrituras públicas, actas extendidas ante un oficial civil o sentencias de separación, nulidad o divorcio. Esta opinión parece más plausible que la que le da efectos absolutos a la parte final del inciso segundo del artículo 225, que manda cumplir con "las mismas solemnidades" para revocar estos acuerdos ${ }^{14}$.

\section{REQUISITOS DE FONDO}

\section{Pactos admisibles: la regla general}

En cuanto a su contenido, hay pactos que deberían considerarse como obligatorios. Todo acuerdo que traslade el cuidado personal a uno de los padres (por ejemplo, al padre) debería, simultáneamente, regular la forma en que el progenitor privado de la tuición (en el ejemplo, la madre) ejercerá su deber de mantener con el hijo una relación directa y regular (artículo 229). Así se debería concluir al concordar el artículo 225 inciso $2^{\circ}$ con el artículo 229, el cual permite establecer un régimen de comunicación con el hijo que posibilite mantener una relación directa y regular con él "con la frecuencia y libertad acordada con quien lo tiene a su cargo" (artículo 229). En el ámbito de las convenciones regulatorias del artículo 21 de la LMC, estas dos materias son de acuerdo obligatorio.

Otros pactos deberían ser voluntarios. Los padres podrán convenir que "el cuidado personal de uno o más hijos corresponda al padre" (artículo 225). La norma permite volver por convención a cualquiera de las fórmulas que admitió la regla histórica chilena

\footnotetext{
${ }^{11}$ ABELIUK (2000) p. 328.

12 AsCencio (2000) p. 159.

13 Court (2000) p. 147.

${ }^{14}$ En este sentido, ASCENCIO (2000) p. 159.
} 
(preferencia materna para la tuición de los hijos de ambos sexos durante la infancia; preferencia paterna para la tuición de los hijos varones a partir de la pubertad; preferencia materna para el cuidado personal de las hijas de toda edad, en el antiguo artículo 223) o bien pactar otras distintas: todos los hijos con la madre hasta determinada edad; todos los hijos con el padre a partir de esa edad. Esta materia se encontraba implícita desde el comienzo de la tramitación del proyecto que llegó a ser la Ley 19.585, pero la cuestión fue aclarada por el Informe Complementario de la Comisión de Legislación, Constitución y Justicia del Senado, la cual dispuso que se insertara la frase "de uno o más hijos" en el inciso segundo de lo que hoy es el artículo 225 del Código Civil ${ }^{15}$. Por convención entre los padres, los hermanos pueden separarse para vivir algunos con su padre y otros con su madre ${ }^{16}$.

Los padres pueden hacer estos pactos por un plazo determinado o indefinido. El plazo también es un pacto voluntario. Si nada se dice, debería entenderse que la convención dura hasta la emancipación de los hijos, a los 18 años de edad (artículo 270 inciso $\left.4^{\circ}\right)$.

En todo caso, las convenciones sobre tuición de los hijos son esencialmente revocables; pero la revocación está sujeta a las mismas formalidades (artículo 225 inciso 2o, i.f.). Es decir, el acuerdo de ambos padres debe ser dado por escritura pública o acta extendida ante un oficial del Registro civil y subinscrita ${ }^{17}$; o por escrito aprobado judicialmente en el marco de la LMC.

\section{Pacto inadmisible: la atribución convencional a terceros}

La ley no parece permitir convenciones entre el padre o madre que tiene el cuidado personal de los hijos y un tercero, pariente o extraño, para atribuir la tuición. El desplazamiento de la tuición a un tercero debe hacerse por resolución judicial. Así debería concluirse del sentido del artículo 225 inciso $2^{\circ}$ cuando expresa que "ambos padres, actuando de común acuerdo" podrán determinar que el cuidado personal de uno o más hijos corresponda al padre. Es decir, el padre o la madre no pueden por esta vía entregar el cuidado personal de uno o más hijos a un tercero, pariente o extraño, o pactar uno de ellos con este tercero la entrega de la tuición. Conviene reiterar aquí la idea de que el cuidado personal de los hijos es indelegable.

En todas estas fórmulas viene exigida la intervención judicial y tanto el cuidado personal de los hijos como el derecho-deber de mantener con ellos una relación directa y regular se adjudican judicialmente (no por atribución legal ni convencional).

\footnotetext{
15 Diario de Sesiones del Senado, Sesión 12a Ordinaria de 22 de julio de 1998 (Anexo de documentos), p. 1532.

${ }^{16}$ En Garrido con Lagos (2008) la Corte Suprema justifica en la reunificación de los hermanos, asunto que satisface de mejor manera el interés superior del niño, la sentencia estimatoria de la pretensión de la madre que pide la tuición de su hijo contra el padre, que la tenía por convención previamente celebrada entre ambos. Después de la convención, y en un período de reconciliación entre los padres, había nacido una hermana, que se encontraba bajo el cuidado de su madre. Ambos padres eran igualmente idóneos para tener el cuidado de sus hijos.

17 AsCencio (2000) p. 159.
} 
En Tuición del menor Benjamín Cabral May (2004) la Corte de Apelaciones de Santiago validó un acuerdo de este género entre el padre viudo y una hermana de la madre del menor, mediante el cual el padre cedía a la tía la tuición de un hijo menor. La razón que decidió la revocación del fallo desestimatorio de primera instancia fue que el criterio legal, a partir de la Ley 19.585, era la voluntad o autonomía de los padres; que el artículo 225 es solo supletorio de la voluntad de los padres; y que el juez no puede modificar decisiones de los padres, "quienes conocen mejor que la judicatura lo mejor o más conveniente a los intereses del menor". A juicio del tribunal llamado a conocer del recurso, el artículo 226 supone controversia entre los padres; y, por tanto, habiendo muerto la madre del menor, es suficiente la voluntad del padre, pues "no existe razón alguna para que [predomine] la decisión judicial por sobre la voluntad manifestada por el padre sobreviviente".

Parece que los fundamentos de la decisión son equivocados. La tuición solo puede pasar a terceros por inhabilidad de ambos padres y es este el supuesto del artículo 226, el cual permite atribuir judicialmente la tuición a terceros, prefiriendo entre estos a los consanguíneos más próximos y sobre todo a los ascendientes. Contrariamente a como razona la sentencia en Tuición del menor Benjamín Cabral May (2004), el artículo 226 no requiere conflicto entre los padres; sino entre un tercero (pariente o extraño) que pretende la tuición y uno o ambos padres que la tienen. Este es el supuesto que exige probar la inhabilidad de uno o ambos padres, con referencia al artículo 42 de la Ley de Menores. Como contrapunto, podemos observar que este era el supuesto en Tuición de la menor Kassandra Arriola Donoso (2008) (conflicto entre progenitores que pretenden la tuición y abuela paterna que contesta la pretensión).

La ley solo admite un uso restringido de las convenciones sobre tuición y derechodeber de mantener con el hijo una relación directa y regular, para flexibilizar el automatismo de la atribución supletoria legal a la madre y evitar la judicialización de un conflicto sobre tuición.

\section{LA REGLA DE ATRIBUCIÓN SUPLETORIA LEGAL DE LA TUICIÓN}

\section{A. FORMULACIÓN DE LA REGLA}

Para las hipótesis de crisis o disociación de la familia, el Derecho civil chileno ofrece una regla supletoria legal de atribución del cuidado personal de los hijos menores, que opera a falta de acuerdo entre los padres. La regla es una de preferencia materna: "[A] la madre toca el cuidado personal de los hijos menores" (artículo 225 inciso 10), matrimoniales y no matrimoniales (antiguo artículo 224), si los padres viven separados de hecho o judicialmente (antiguo artículo 26 y siguientes LMC), por divorcio (artículo 53 y siguientes LMC) o nulidad (artículo 44 y siguientes LMC). En otras palabras, la regla supletoria legal de atribución automática a la madre podría formularse así: si los padres viven separados (supuesto de hecho determinado), toca a la madre el cuidado personal de los hijos menores (regla de atribución automática y determinada).

La Ley 19.585, de 1998, ha respetado esta regla legal de atribución y preferencia materna que venía de la legislación anterior. Sin embargo, la ha desplazado al carácter 
de regla supletoria, puesto que los padres pueden modificarla por convención (artículo 225 inciso $2^{\circ}$ ). El supuesto de atribución legal es, a partir de la entrada en vigencia de esta ley, la separación de los padres como situación de hecho o de derecho (por sentencia judicial de separación, nulidad o divorcio), con o sin previo matrimonio entre los progenitores. Es decir, la regla supletoria legal que atribuye la tuición de los hijos a la madre rige en hipótesis de ruptura familiar y, especialmente, cuando los padres no han podido alcanzar acuerdos sobre el cuidado personal de los hijos durante su vida separada.

Esto significa que la intervención judicial queda pospuesta para hipótesis de impugnación de la atribución legal por el progenitor privado del cuidado personal del hijo, aunque también pueden impugnarse por vía judicial las convenciones que hayan alcanzado los padres sobre atribución del cuidado personal de sus hijos o sobre el régimen de comunicación con el hijo que tenga el progenitor privado de la tuición.

A continuación se examinará la historia y conveniencia de esta regla de atribución legal automática.

\section{B. Historia DE LA REGLA EN EL DERECHO CHILENO}

\section{Atribución legal automática a la madre: su origen y desarrollo \\ a) Planteamiento}

Podemos partir afirmando que el Código Civil chileno siempre ha ofrecido una regla de atribución automática legal del cuidado personal de los hijos a la madre. El artículo 223 del Código Civil de 1855 disponía lo siguiente:

"A la madre divorciada, haya dado o no motivos al divorcio, toca cuidar personalmente de los hijos menores de cinco años, sin distinción de sexo, y de las hijas de toda edad. Sin embargo, no se le confiará el cuidado de los hijos de cualquiera edad o sexo, cuando por la depravación de la madre sea de temer que se perviertan; lo que siempre se presumirá, si ha sido el adulterio de la madre lo que ha dado causa al divorcio.

En estos casos, o en el de hallarse inhabilitada por otra causa, podrá confiarse el cuidado personal de todos los hijos de uno u otro sexo al padre".

Lo primero que es necesario destacar en la formulación de esta regla es que no es una regla de atribución legal al cónyuge inocente en un proceso de divorcio: "a la madre, haya dado o no motivos al divorcio, toca cuidar personalmente de los hijos”, establecía el artículo 223 del Código de 1855. El Código Civil chileno se apartaba, desde un principio, de la regla clásica de su época, que era la que ofrecía el artículo 302 del Código de Napoleón ("ejecutoriado el divorcio, quedarán los hijos, o se pondrán bajo el poder y protección del cónyuge no culpable") ${ }^{18}$. La única causa de divorcio que configuraba una falta de idoneidad para el cuidado personal de los hijos era el adulterio de la

${ }^{18}$ En el mismo sentido, los artículos 156 del Código del cantón de Vaud, 284 del Código holandés y 155 del Código de la Luisiana. Bello consigna en nota al Proyecto de 1853: "Se han hecho modificaciones varias a las leyes del tít. 19, part. 4". La Ley de Partidas ofrecía la siguiente regla: "El que non fue en culpa [los hijos] debe criar e aver en guarda" (Partida 4a, 3, 19). 
madre; hecho que, como se verá, fue perdiendo fuerza en sucesivas modificaciones hasta eliminarse por completo como causa especial de inhabilidad en la reforma de la Ley 18.802 de 1989.

La regla del artículo 223 ha evolucionado en dos sentidos. En primer lugar, ha evolucionado haciendo extensivas las hipótesis de atribución legal a casos no contemplados originalmente en el supuesto de divorcio, único previsto en el Código de $1855^{19}$. La regla ha evolucionado también en lo que se refiere a la edad y sexo de los hijos. En segundo lugar, se ha mitigado el efecto del adulterio de la madre en la configuración de su inhabilidad. Primero se desarticuló la presunción de inhabilidad que se producía por el hecho del adulterio, para después hacer extensivo este hecho también al adulterio del padre y, finalmente, eliminar la incidencia del adulterio en el juicio de idoneidad del padre o de la madre para la atribución judicial del cuidado personal de los hijos.

\section{b) Hipótesis de funcionamiento histórico de la regla}

La única hipótesis en que operaba la regla de atribución del artículo 223 (hoy artículo 225) del Código Civil de 1855, como está dicho, era el divorcio de los padres. La ley nada decía respecto de situaciones de separación que ocurrían simplemente de hecho o por nulidad del matrimonio. El Código Civil tampoco contemplaba una regla de atribución legal en la hipótesis de hijos no matrimoniales: el cuidado personal de estos hijos se atribuía judicialmente.

El artículo 223 operaba también como criterio de atribución judicial. Es decir, al atribuir el cuidado personal de los hijos, los jueces acudían a los criterios que les ofrecía esta norma: (10) preferencia materna durante la infancia; (20) preferencia paterna a partir de la pubertad para la tuición de los hijos varones; (3०) inhabilidad del padre o la madre, o de ambos, como criterio de modificación de atribuciones anteriores.

La jurisprudencia, entonces, hizo pacíficamente extensiva la regla establecida para el caso de divorcio (artículo 223) a los supuestos de separación de hecho y nulidad de matrimonio. La insuficiencia formal de las fuentes legales permitió que alguna sentencia disidente afirmara que estas reglas solo se referían al divorcio ${ }^{20}$, introduciendo un factor de inseguridad en el marco legal aplicable a los problemas de tuición que fue necesario corregir por ley. La Ley 10.271 de 1952 resuelve en parte este problema al hacer explícitamente extensiva la regla de atribución legal del artículo 223 a los supuestos de nulidad de matrimonio ${ }^{21}$.

\footnotetext{
19 Conforme al Derecho canónico vigente en la época y, posteriormente, conforme a la Ley de Matrimonio civil de 1884 , se trataba de un divorcio sin ruptura de vínculo o simple separación. En el antiguo artículo 223, divorcio significa lo que hoy conocemos como separación judicial.

20 SOMARRIVA (1983a) p. 449.

21 La ley no distinguía entre matrimonio nulo y putativo. Si el matrimonio era putativo para ambos cónyuges, no se cuestionaba la aplicación de la regla de atribución del artículo 223. Si el matrimonio era simplemente nulo para ambos cónyuges, la regla también se aplicaba porque no distinguía esta situación. El problema se presentaba si el matrimonio era putativo para uno solo de los cónyuges. En estos casos la opinión más autorizada era que el cuidado personal de los hijos correspondía al cónyuge de buena fe, sin distinción en cuanto a la edad y el sexo de los hijos (SOMARRIVA, 1983b, p. 87).
} 
La hipótesis de separación de hecho de padres unidos en matrimonio se soluciona unos años después por vía de legislación especial de menores. El artículo 24 de la Ley 14.907 de 1962 sobre protección de menores hace aplicable la regla del entonces artículo 223 a todos los casos posibles de rupturas familiares: divorcio de los padres, separación de hecho, nulidad de matrimonio e, incluso, supuestos de filiación no matrimonial (menores reconocidos o no reconocidos por sus padres). Esta norma luego es trasladada al artículo 46 de la Ley 16.618 de 1967. La Ley 19.585 de 1998 deroga esta ley (el artículo 46 de la Ley 16.618), pero no modifica el derecho sustantivo vigente.

Según destaca un cuidadoso estudio, lo que la reforma de 1998 hace es trasladar al Código Civil lo que resolvía la legislación especial de protección de menores ${ }^{22}$.

Las hipótesis que hacían operativa la regla de atribución legal a la madre, por tanto, sufren un desarrollo claramente expansivo, aunque en algunos casos el artículo 223 operaba como criterio judicial y no exclusivamente como regla de atribución automática legal. La preferencia materna tiene, sin embargo, otro ámbito de desarrollo.

\section{Tendencia expansiva de la preferencia materna en cuanto a la edad y sexo de los hijos}

En cuanto a la edad y sexo de los menores sujetos al cuidado de la madre, la regla también ha tenido una evolución expansiva. El artículo 223 otorgaba a la madre el cuidado personal de los hijos menores de cinco años, sin distinción de sexo, y de las hijas de toda edad. La regla separaba a los hermanos a partir de los cinco años, puesto que la tuición de los hijos varones pasaba entonces al padre. La regla fue modificada en $1935^{23}$ para atribuir a la madre, en las mismas condiciones, el cuidado de todos los hijos menores hasta los diez años y de las hijas de toda edad.

La Ley 10.271 de 1952 volvió a modificar la regla. El cuidado personal de todos los hijos menores de catorce años quedaba atribuido a la madre. Al parecer, al elevar a catorce años la edad para que los varones pasaran al cuidado del padre, la Ley 10.271 tuvo especialmente en cuenta que en el cambio de tuición debía tener importancia la opinión del hijo y se estimó que para ello era conveniente que el menor tuviera discernimiento y capacidad para tomar una decisión razonada, lo que no le era posible antes de llegar a la pubertad ${ }^{24}$.

La Ley 18.802 de 1989 reemplazó el texto original del Código atribuyendo a la madre el cuidado de todos los hijos menores de edad y derogando la norma que atribuía al padre el cuidado personal de los hijos varones desde los catorce años de edad. "Se pensó -escribe uno de los principales gestores e intérpretes de la reforma- que era más importante la madre en la crianza y educación de los hijos[;] y que era conveniente no separar a los hermanos" 25 . Si esto fue así, la Ley 18.802 desestimó la importancia del

\footnotetext{
22 Ascensio (2000) pp. 113-116.

${ }^{23}$ Por Ley 5.680 de 13 de septiembre de 1935.

24 SOMARRIVA (1983b) p. 86.

25 ROZAS Vial (1990) p. 33. Hoy es raro encontrar casos como Schuffeneger con Bordagaray (1996), donde la Corte Suprema desestima un recurso de queja que pretende impugnar una decisión de la Corte de Apelaciones de Talca que entrega la tuición de los hijos varones al padre, manteniendo a la hija, que a la fecha tenía tres años de edad, al cuidado de su madre.
} 
padre en la educación de los hijos, especialmente de los hijos varones; figura que no puede ser sustituida por el derecho de visitas.

La reforma fue, además, contradictoria. Por una parte pretendía la igualdad entre el varón y la mujer (derogación de la potestad marital y de la incapacidad relativa de la mujer casada), pero, por otra, minusvaloraba la figura del padre en la crianza y educación de los hijos. Como sabemos, la Ley 19.585 mantuvo el criterio de atribución de todos los hijos menores a la madre, sin distinción de sexo ni edad. Ambas reformas, a mi juicio, erraron en un propósito de política legislativa, cual es el de incentivar la participación del padre en la crianza y educación de los hijos.

Las situaciones de separación de los padres afectan el derecho de los hijos a contar con un padre y con una madre; y estas situaciones no se alivian con una regla de atribución como la que introduce en el Código Civil la Ley 18.802 de 1989. Esta aspiración de estabilidad de los hijos no es ajena al quehacer judicial. Por ejemplo, en Tuición de los menores Ramos Astudillo (1996), la Corte de Apelaciones de Antofagasta se ve obligada a fallar dejando las cosas como están "ante la imposibilidad de reconstituir la situación que siempre será la mejor para [los hijos], esto es, la convivencia directa y permanente con sus padres". En los hechos tanto el padre como la madre eran personas idóneas para cuidar de sus hijos; pero la tuición la tenía el padre de común acuerdo con la madre.

\section{Mitigación de los criterios de inhabilidad}

La regla de atribución automática legal a la madre cedía frente a una decisión judicial fundada en su inhabilidad, criterio que abarcaba vagamente diversas situaciones, incluido el adulterio. Era este último, sin embargo, el factor de falta de idoneidad que recibía especial atención en la regulación codicial. Conforme al antiguo artículo 223, la tuición de todos los hijos, varones y mujeres de cualquier edad, pasaba por atribución judicial al padre "cuando por la depravación de la madre [fuera de temer que se pervirtieran]", hecho que se presumía "siempre", si por su adulterio se había dado lugar al divorcio $^{26}$. La Ley 10.271 de 1952 eliminó la presunción que favorecía al padre, agregando el siguiente inciso final al artículo 223: "La circunstancia de haber sido el adulterio de la madre lo que ha dado causa al divorcio deberá ser considerada por el juez como antecedente de importancia para resolver sobre su inhabilidad".

A partir de entonces, la inhabilidad en que incurría la madre por adulterio ya no era una presunción de Derecho, sino un hecho del juicio que podía servir de base para una presunción judicial. Conforme al inciso final del antiguo artículo 224, además, la misma regla se haría aplicable al padre. Se equiparaban así los efectos del adulterio de la madre y del padre. El adulterio, como antecedente de importancia para resolver sobre la inhabilidad, fue finalmente eliminado del Código por la Ley 18.802 de $1989^{27}$.

\footnotetext{
${ }^{26}$ La doctrina y la jurisprudencia estimaban que en el adverbio "siempre" se debía leer una presunción de Derecho, que no admitía prueba de idoneidad de la madre en contrario (SOMARRIVA, 1983a, p. 450).

27 Esta ley derogó el artículo 224 entero y reemplazó el artículo 223 por el texto que actualmente está vigente en el Código Civil.
} 
En cuanto a otras causas de inhabilidad, la legislación especial muy pronto fue completando los escuetos criterios civiles, entregando al juez una serie de criterios objetivos que le permitían evaluar la inhabilidad del padre o de la madre para modificar atribuciones legales o judiciales previas. Estos criterios fueron inicialmente introducidos por la Ley 4.447 de 1928 sobre protección de menores; ley que posteriormente fue refundida en la Ley 14.907 de 1962, cuyo texto pasó íntegramente al artículo 42 de la Ley 16.618 de 1967 , vigente hoy ${ }^{28}$.

La Ley 14.907 añadió una causa adicional de inhabilidad, que hoy encontramos al final del artículo 225 del Código: “[el juez] no podrá confiar el cuidado personal al padre o madre que no hubiese contribuido a la mantención del hijo mientras estuvo bajo el cuidado del otro padre, pudiendo hacerlo”. Esta norma venía a terminar con la práctica que consistía en demandar la tuición de los hijos para enervar el apremio dirigido contra el padre por no pago de alimentos ${ }^{29}$. La inhabilidad afectó originalmente al padre. La Ley 19.585 de 1998 hizo extensiva esta causa a la madre.

La atribución legal, por tanto, podía modificarse por decisión judicial fundada en la inhabilidad de la madre o del padre. El adulterio fue, al comienzo, un factor grave en la inhabilitación de la madre y, posteriormente, del padre, pero sus efectos en cuanto al cuidado de los hijos quedaron eliminados con la reforma de la Ley 18.802 de 1989. Hoy solo subsisten como factores de inhabilidad los criterios de la Ley de Menores (inhabilidad física o moral de uno o ambos padres) y la inhabilidad que afecta al progenitor que no provee mientras el hijo ha estado bajo la tuición del otro padre (artículo 225 inciso $3^{\circ}$ ). Sin embargo, a partir de la Ley 19.585 hay otro criterio de atribución judicial que entra poderosamente en juego para modificar atribuciones legales o convencionales: el principio del interés superior del niño (artículos 225 inciso $3^{\circ}$ y 242). Dedicaremos a este y otros criterios judiciales de atribución de la tuición la tercera parte de este estudio.

\section{Ventajas de la eXistencia de unA Regla de ATRibución LEGAL}

La existencia de una regla de atribución legal del cuidado personal, en el carácter de regla supletoria legal, tiene ventajas desde diversas perspectivas. En primer lugar, la regla reduce la litigiosidad y judicialización de los conflictos entre padres que no han podido ponerse de acuerdo previamente. En segundo lugar, la regla fomenta los acuerdos entre los padres que saben que, de no llegar a un convenio, la ley atribuirá la tuición de los hijos de una determinada manera y que, si pretenden otra cosa, necesariamente deberán llevar el asunto a juicio.

Ahora bien, en defensa de la subsistencia de una regla de atribución legal a la madre, es necesario desarticular las dudas sobre la constitucionalidad de la preferencia legal por la madre. El problema es que entonces habría que optar por entregar supleto-

\footnotetext{
${ }^{28}$ Hay que tener en cuenta que los factores de inhabilidad física o moral enumerados en el artículo 42 de la Ley 16.618 de Menores están concebidos para la adopción de medidas judiciales de protección que consisten en la entrega del cuidado personal de menores a terceros, distintos de su padre o de su madre (artículo 226 del Código Civil) y no para conflictos de tuición entre el padre y la madre (artículo 225 del Código Civil).

${ }^{29}$ SOMARRIVA (1983a) p. 452.
} 
riamente la tuición al padre; y la objeción de constitucionalidad se produciría en sentido inverso. Desarrollaré estos temas a continuación.

\section{La regla de atribución supletoria legal reduce la judicialización de los conflictos}

La ventaja de una regla de atribución supletoria legal del cuidado personal de los hijos puede examinarse desde dos puntos de vista. Por una parte, hay que destacar los beneficios de la existencia de una atribución legal. Con intuición y seguramente apoyado en la experiencia, Abeliuk ${ }^{30}$ opina que esta regla evita "el trámite judicial". Este escueto comentario tiene, a mi juicio, gran calibre. El niño tiene, por ley, alguien cuyo deber es cuidarlo, sin esperar los resultados inciertos de un juicio ni exponerse a las disputas entre sus padres sobre tuición.

Discutiendo las desventajas de la regla de atribución judicial que manda entregar el cuidado personal de los hijos a cualquiera de los padres según "el interés superior del niño", Glendon argumenta que uno de sus problemas es que no hace nada para desincentivar los pleitos entre padres y que, probablemente, los estimula. En este contexto, asegura, cualquier regla automática, incluso judicial, sería una mejora ${ }^{31}$.

La conclusión más importante del estudio de un asesor legislativo y profesor de clínica jurídica en la ciudad de Nueva York, es que los juicios contenciosos entre padres sobre la tuición de sus hijos deben evitarse por todos los medios posibles ${ }^{32}$. Los hijos tienen derecho a verse libres del dolor de un litigio entre sus padres por su custodia y, en esto, la existencia de una regla de atribución supletoria legal juega un rol fundamental. De no existir una regla de este estilo, ni acuerdo entre los padres, el asunto necesariamente tendrá que resolverlo el juez.

Los vicios de los juicios entre padres sobre el cuidado personal de sus hijos son universalmente conocidos. Jon Elster los describe muy elocuentemente: una parte puede querer prolongar el litigio si tiene más medios económicos que la otra para sostenerlo, para forzar una transacción en su favor. Mientras más dure el juicio, más posibilidades tiene la parte que consigue la atribución provisional de la tuición, de ganarla en definitiva. Estos incentivos proporcionan un argumento adicional: el litigio va siempre en perjuicio de uno de los padres. Más casos son llevados a los tribunales de los que lo serían si existiera una fuerte presunción a favor de uno de los padres, o un procedimiento de decisión automática, porque no existiendo una regla legal de atribución, las dos partes están persuadidas de que tienen posibilidades de obtener el cuidado personal de sus hijos. En cualquier conflicto que sea llevado a los tribunales, el procedimiento puede ser dilatado al infinito, puesto que la decisión del tribunal no se apoya simplemente en

\footnotetext{
${ }^{30}$ ABELIUK (2000) p. 327.

31 GLENDON (1986) p. 1182. La autora cita estudios que demuestran que en West Virginia el tránsito del standard "interés superior del niño" hacia el standard "primary caretaker" (cuidador principal), más automático y fijo que el anterior, produjo un enorme descenso en los litigios por cuidado personal de los hijos entre padres.

32 SCHEPARD (2004) p. xiv.
} 
la falta de idoneidad de uno de los padres, sino en el servicio del interés del niño ${ }^{33}$. Otro autor argumenta a favor de un criterio automático de decisión porque produce incentivos para que los padres alcancen acuerdos directos en un proceso de mediación ${ }^{34}$. Ellos saben que, de no llegar a un acuerdo, opera una decisión automática, como en nuestro caso es la atribución legal del artículo 224. La desconfianza en criterios discrecionales es general.

La ausencia de una regla legal de atribución, además, incentiva los hechos consumados para ampararse en el criterio judicial que tiende a mantener el statu quo a favor del niño. Tiene ventajas comparativas el padre o madre que ha preparado el juicio creando una situación de hecho que tiende a forzar una decisión a su favor. La regla de atribución legal previene este tipo de conductas ${ }^{35}$.

\section{La existencia de una regla de atribución supletoria legal es incentivo de acuerdos entre padres}

Al momento de negociar un acuerdo sobre la tuición de los hijos, el padre o madre favorecido por la regla legal sabe que su posición tiene un valor añadido; y esto favorece las negociaciones. "Al definir los resultados de una ruptura en las negociaciones, la ley crea una línea de base con la cual comparar los resultados de un acuerdo privado. Puede suponer una gran diferencia en el poder de negociación de las partes si el punto de partida es una presunción legal [de preferencia materna o paterna; o la ausencia de una regla de atribución legal]"36.

Por ejemplo, si la atribución supletoria legal favorece a la madre, esta tendría que estar dispuesta a ceder, aunque tenga la negociación "ganada por ley", porque no siempre tiene ganado el juicio que seguiría a la atribución legal, si el padre tiene evidencia que lo favorece en función del interés superior del niño. Su inflexibilidad al momento de llegar a acuerdos con el padre de sus hijos la podría conducir a perder el cuidado personal de sus hijos en un juicio posterior. Además, aunque parezca frío reconocerlo así, estas negociaciones están entremezcladas con los acuerdos en materia económica y a la madre le puede convenir ceder la tuición de uno o más hijos al padre, por convención, a cambio de un arreglo económico más satisfactorio, para sí y para el conjunto de todos los hijos. En todas estas negociaciones, los padres deben siempre tener en cuenta los costos tremendos de un juicio para los hijos, imposibles de medir en términos económicos.

En la hipótesis de no existir regla legal alguna, no hay incentivos que favorezcan los acuerdos y los conflictos tienden a derivar en pleitos de alto costo, también emocional, para todas las partes afectadas. Nadie pierde nada con su inflexibilidad, porque no tiene ganado nada de antemano.

\footnotetext{
33 ELSTER (1987) pp. 23 y 24.

${ }^{34}$ Houlgate (2005) pp. 130-133.

${ }_{35}$ Como ejemplos de la existencia del criterio que favorece el statu quo en la jurisprudencia chilena pueden citarse Mondaca Romero (1998), Tuición de los menores Ramos Astudillo (1996); Tuición de la menor Arriola Donoso (2008); Hernández con Sarmiento (2008).

36 ELSTER (1987) p. 33.
} 


\section{La preferencia materna como opción de politica legislativa}

Ahora bien, las razones que justifican la existencia de una regla supletoria legal de atribución, para el caso en que los padres no alcancen acuerdos, no justifican por sí solas la preferencia materna. Como hemos observado más arriba, la preferencia materna es algo que ha ido extendiéndose pacíficamente en Chile a través de sucesivas reformas legales, hasta llegar a la situación actual. Ni los autores ni la jurisprudencia chilena cuestionaron esta regla de atribución, sino hasta después de la reforma de la Ley 19.585 de 1998. Las críticas discurren hoy sobre motivos de constitucionalidad de la regla.

Durante la tramitación de la Ley 19.585 se dijo que la preferencia materna "evita numerosas dificultades y responde a la práctica, que demuestra que lo más frecuente es que sea la madre la que [...] asuma cuando los padres no viven juntos" ${ }^{\prime 7}$. En el Segundo Informe de la Comisión de Constitución del Senado aparece con claridad la idea de que las reglas de atribución legal y convencional del artículo 225 están sujetas a revisión judicial en función del interés del hijo, "por maltrato, descuido u otra causa calificada" 38 y que este criterio se establecía para moderar la fuerza de la preferencia legal por la madre. Quedaba claro que la preferencia materna era una regla de atribución supletoria legal, puesto que prefería la atribución por convención que permite el nuevo artículo 225 inciso $2^{\circ}$.

Como cuestión de interés en este asunto conviene recordar que el proyecto original de reforma del Código Civil mantenía la vigencia de la regla de preferencia materna en el carácter de supletoria legal:

"Artículo 222. Si los padres viven separados, a falta de acuerdo, corresponde a la madre el cuidado personal de los hijos menores; salvo que por motivos calificados el juez decidiere de otro modo" 39 .

Esto demuestra el consenso transversal que existía en la doctrina chilena sobre la conveniencia de mantener esta preferencia con carácter legal. También se observa que ya en el proyecto que dio origen a la reforma de la Ley 19.585, la regla sufría una moderación en su fuerza al autorizarse los acuerdos sobre tuición entre los padres. En la idea que se promovió entonces, como sucede actualmente con los textos vigentes, el juez podía modificar "por motivos calificados" la atribución convencional o legal.

La duda de constitucionalidad de la regla surge, entonces, después de tramitado el proyecto y convertido en Ley.

\footnotetext{
37 Informe de la Comisión de Constitución, Legislación y Justicia del Senado, Diario de Sesiones del Senado, Sesión Ordinaria 12a de 3 de diciembre de 1996, p. 1649.

38 Segundo Informe de la Comisión de Constitución, Legislación y Justicia del Senado, de 4 de noviembre de 1997: Diario de Sesiones del Senado, Sesión 12a (Anexo de documentos) pp. 1793-1934, p. 1837. En adelante, Segundo Informe de la Comisión de Constitución del Senado.

39 Boletín No 1060-07: Diario de Sesiones de la Cámara de Diputados, Sesión 25a Ordinaria de 10 de agosto de 1993, pp. 2481-2504, p. 2492.
} 


\section{CONSTITUCIONALIDAD DE LA REGLA DE PREFERENCIA MATERNA}

Las objeciones de constitucionalidad de la regla de preferencia materna se refieren a los incisos $1^{\circ}$ y $3^{\circ}$ del artículo 225 del Código Civil: atribución legal a la madre en caso de separación de los padres y atribución judicial al otro progenitor "cuando el interés del hijo lo haga indispensable por descuido, maltrato u otra causa calificada". En realidad, todas las objeciones se deberían concentrar en el inciso $1^{\circ}$, pues la regla del inciso $3^{\circ}$ es una regla de atribución judicial.

Barros Bourie ${ }^{40}$ recapitula estas objeciones de la siguiente forma. Primero: la interpretación de la regla como un derecho [subjetivo] de la madre del que solo puede ser privada a título de sanción es una discriminación en contra del padre, que tiene igual derecho al cuidado de los hijos ${ }^{41}$. Segundo: la regla podría ser perjudicial para el interés del niño, que puede ser usado como "pieza táctica” en la negociación económica que sigue a la separación de los padres ${ }^{42}$. En esta línea podría agregarse la opinión que mantiene que la existencia de una regla de atribución legal se opone al interés del niño que aconsejaría siempre la intervención judicial para controlar los acuerdos de atribución realizados por los padres ${ }^{43}$.

Las objeciones de constitucionalidad se formulan, entonces, desde el punto de vista de dos principios. Primero, desde la perspectiva de la prohibición de toda discriminación arbitraria, que encuentra su fuente en el artículo 19 número $2^{\circ}$ de la Constitución Política de la República ${ }^{44}$. Segundo, desde el principio del interés superior del niño, al que, en esta discusión, debería atribuírsele rango constitucional, ex artículo $5^{\circ}$ inciso $2^{\circ}$ de la Constitución Política con relación especialmente a los artículos 3 y 9 de la Convención sobre los derechos del niño ${ }^{45}$.

A continuación me hago cargo de estos argumentos.

\section{La regla no ofende el principio de igualdad entre los progenitores}

La preferencia materna, tal cual está formulada en el derecho chileno después de la reforma de la Ley 19.585 de 1998 no es un derecho subjetivo que la ley atribuya a la

\footnotetext{
40 BARros BoUrie (1999) p. 47.

${ }^{41} \mathrm{La}$ calificación de la preferencia materna en el cuidado personal de los hijos como un derecho subjetivo, sin embargo, no concuerda con las disposiciones legales que permiten la revisión judicial de esta regla legal en consideración del interés superior del niño (artículos 225, inciso $3^{\circ}$ y 242) y de su opinión (artículo 242 inciso $2^{\circ}$ ). Entre los padres, el interés superior del niño ha desplazado al criterio judicial de idoneidad de la madre o el padre; aunque operen como criterios complementarios, según dispone el artículo 225 inciso $3^{\circ}$. A juicio de este estudio, más que un derecho subjetivo, la preferencia materna es una carga o un deber atribuido por ley. Rechaza también la idea del cuidado personal de los hijos como derecho de la madre: GÓMEZ DE LA TORRE (2007) p. 139.

42 Barros Bourie (1999) p. 48. Lo siguen en estos argumentos: SCHMIDT (2001) p. 277 y LATHROP (2005) p. 13.

43 SCHMIDT (2001) p. 276.

${ }^{44}$ GÓMEZ DE LA TORRE (2007) p. 141, agrega que una interpretación restrictiva del artículo 225 ofendería también el principio de igualdad de los progenitores, tal como se encuentra consagrado en convenciones internacionales ratificadas por Chile (Convención Americana de Derechos Humanos, artículo 17.4; Convención sobre la Eliminación de Todas las Formas de Discriminación contra la Mujer, artículo 16).

45 Promulgada como ley de la República por Decreto Supremo No 830 (Relaciones Exteriores) de 27 de septiembre de 1990 .
} 
madre. Es la atribución automática de un deber, por ley. Además, esta atribución puede modificarse por decisión judicial a solicitud del padre "por maltrato, descuido u otra causa calificada” en función del interés del hijo. La intervención judicial que modifica una atribución legal o convencional no constituye una sanción para la madre, sino la modificación de una carga entre los padres en función del interés del hijo, cuando existen motivos calificados que lo justifiquen.

El argumento de que esta regla ofende el principio de la igualdad de géneros tampoco tiene sustento. La regla opta por atribuir el cuidado personal de una forma que evita que los conflictos entre progenitores deriven necesariamente en juicio, favoreciendo la situación de los niños. Esta opción no podría considerarse discriminatoria con respecto al padre pues este mantiene su derecho a relacionarse con el niño (artículo 229). La experiencia demuestra que la ley no puede más que atribuir el deber de cuidar personalmente a los niños a uno de los padres, padre o madre, y que en la práctica, incluso de países que se han propuesto eliminar todo vestigio de preferencia materna por motivos ideológicos, los jueces siguen atribuyendo mayoritariamente el cuidado personal de los hijos a la madre, si no hay acuerdo entre los padres.

A esto hay que agregar que la preferencia materna es una regla supletoria de la voluntad de los padres que, como se argumentó antes, favorece acuerdos en vez de entorpecerlos. La eliminación de esta regla aumentaría considerablemente el número de pleitos sobre cuidado personal de los hijos, en circunstancias de que con la regla de atribución legal solamente llegan a los tribunales los casos que merecen una intervención judicial (por grave falta de acuerdo entre los progenitores, por "maltrato, descuido u otra causa calificada”, por interés superior del niño). No puede perderse de vista que la regla está diseñada para operar en Chile, en un sistema de tribunales de familia sobrecargado e, incluso, sobrepasado.

Tampoco puede olvidarse que la Ley 19.585 reformó el criterio de modificación judicial de la atribución legal (hoy supletoria) de la tuición. Antes de la reforma, el criterio judicial de modificación era la inhabilidad de la madre (considerando la evolución de este concepto en el tiempo y los elementos objetivos de ponderación judicial que ofrece el artículo 42 de la Ley 16.618), un criterio que podría calificarse de "sanción". Sin embargo, ahora el artículo 225 inciso $3^{\circ}$ establece un criterio flexible de atribución en función del interés del niño, para desplazar el cuidado personal de los hijos al padre por intervención judicial. La impugnación de la atribución legal, o convencional, se funda en el interés del hijo, no en la inhabilidad de la madre o del padre ${ }^{46}$.

Como criterio de política legislativa (no de atribución judicial), el principio del interés superior del niño aconseja, y no al contrario, la existencia de una regla de atribu-

\footnotetext{
46 GÓMEZ DE LA TORRE (2007) p. 140, se hace eco de la opinión de un sector de la doctrina chilena que favorecería una interpretación restrictiva del artículo 225 al entender que el legislador habría querido hacer prevalecer el principio del interés superior del niño por sobre el principio de igualdad, para que los tribunales atribuyan preferentemente a la madre el cuidado personal de los hijos. En opinión de la autora, esta interpretación sería inconstitucional. En el contexto del artículo 225 inciso 30 (intervención judicial para atribuir la tuición al otro progenitor), el interés del niño no necesariamente debería suponer preferencia materna.
} 
ción legal de la tuición. Ahora bien, parece importante destacar que, a juicio de este estudio, el principio no aconseja específicamente que esta regla sea la preferencia materna, pues también podría el legislador optar o haber optado por dar preferencia al padre. Sucede, a mi juicio, que entre las diversas opciones de atribución legal, la preferencia materna parece ser aconsejable, por lo menos según la experiencia histórica; aunque en el ámbito de política legislativa la regla admita diversas formulaciones e, incluso, pueda buscar un mayor equilibrio entre los padres, dando directamente preferencia al padre, especialmente según la edad y sexo de los hijos. Conviene recordar en este lugar que esta era la regla histórica chilena hasta la reforma de la Ley 18.802 de 1989. Lo importante, a juicio de este estudio, es que exista una regla de atribución legal que funcione automática y supletoriamente en caso de falta de acuerdo entre los progenitores, evitando con esto el litigio al que necesariamente llegarían de no existir la regla legal.

\section{La regla no ofende el principio del interés superior del niño}

El principio del interés del niño tampoco podría constituirse en un argumento que fundamente la inconstitucionalidad del artículo 225 inciso primero. Ya hemos dicho que la existencia de una regla de atribución legal evita la judicialización y litigiosidad en materias de cuidado personal de los hijos; y esto, principalmente, a favor del niño. Es decir, la existencia de la regla sirve al interés del niño de mejor manera que su ausencia. Es más, cabe mantener la hipótesis de que la ausencia de una regla de atribución legal favorece las expectativas e intereses de los progenitores, pero no una situación de estabilidad y paz a favor del niño. Si ambos intereses son igualmente legítimos, cabe ponerlos en jerarquía. En este supuesto, parece que conviene preferir el interés del niño (o de los hijos) por sobre el interés de los padres. Es a los padres a quienes corresponde sacrificar sus intereses personales en función del interés de sus hijos y no estos sacrificar el desarrollo armónico de su personalidad en función del interés de sus padres.

Recapitulando, entonces, puede afirmarse que las objeciones de constitucionalidad de la preferencia materna no pueden apoyarse en la regla constitucional que prohíbe diferencias arbitrarias: es una regla supletoria de la voluntad de los padres que no confiere a la madre derecho subjetivo alguno, sino una función o un deber de la que no está privado el padre y que no impide la modificación judicial de la atribución legal en función del interés del niño. La preferencia materna tampoco ofende el interés del hijo. Al contrario, evita litigios y la excesiva judicialización de los conflictos de los padres sobre el cuidado personal de sus hijos y favorece los acuerdos. Todo lo cual no quiere decir que esta regla no admita otras formulaciones, como las que existieron en el Derecho chileno hasta la reforma de la Ley 18.802 de 1989.

\section{LOS CRITERIOS DE ATRIBUCIÓN JUDICIAL DE CUIDADO PERSONAL DE LOS HIJOS}

La tercera parte de este trabajo es un estudio de los criterios de atribución judicial del cuidado personal de los hijos, a petición de uno de los padres (artículo 225 inciso $3^{\circ}$ ) o de un tercero, pariente o extraño (artículo 226). En este ámbito son dos las reglas 
de adjudicación que ofrece el Derecho chileno: el principio del interés superior del niño y la regla de idoneidad (o, en negativo, inhabilidad) del o de los progenitores que tienen actualmente la tuición por atribución legal o convencional.

A su vez, son dos los supuestos de intervención judicial en materias de cuidado personal de los hijos. En primer lugar, el juez es llamado a intervenir en el caso de conflictos entre progenitores (artículo 225 inciso $3^{\circ}$ ). En segundo lugar, el juez es llamado a intervenir a requerimiento de un tercero (pariente o extraño) en el supuesto de falta de idoneidad o inhabilidad física o moral de ambos padres (artículo 226). Dentro de este segundo grupo de casos están la adopción y las medidas de protección de menores, como intervenciones judiciales que separan a los hijos de sus padres biológicos.

\section{A. Presupuestos de interVEnCión JudiCial EN ASUNTOS DE TUICIÓN}

De acuerdo al sistema previsto por la legislación chilena, la tuición se atribuye por convención entre los padres (artículo 225 inciso $2^{\circ}$ y artículo 21 de la Ley 19.947) o por ley (artículo 225 inciso 10). La intervención judicial tiene por objeto, por tanto, el modificar una situación ya configurada; en consecuencia, pide que se acredite en el proceso las circunstancias que justifiquen la atribución judicial.

Esto es lo que, a mi juicio, advierte el artículo 225 inciso $3^{\circ}$ cuando exige -con criticable técnica legislativa- que el juez intervenga "cuando el interés del hijo lo haga indispensable, sea por maltrato, descuido u otra causa calificada". El supuesto de hecho que exige la intervención judicial consiste en una serie de circunstancias: "maltrato, descuido u otra causa calificada", es decir, motivos calificados que hacen indispensable, por el interés del hijo, la modificación de una atribución convencional, legal o judicial previa. Las circunstancias calificadas que hacen indispensable la modificación que se pide son cuestiones de hecho que debe acreditar el demandante en el juicio mediante cualquier medio de prueba producido en conformidad a la ley (artículo 28 LTF). La ley claramente privilegia la atribución convencional o legal del cuidado personal de los hijos. La intervención y posterior atribución judicial exige circunstancias especiales que deben acreditarse en el juicio.

La referencia a lo que ocurre en la práctica puede ayudar a ilustrar este problema, pues los tribunales exigen prueba que produzca en ellos la convicción de que se justifica una atribución judicial que modifica la atribución legal o convencional previa. Por ejemplo, en Pino con Castro (2007) (la madre pide entrega inmediata de sus hijos contra el padre, que se defiende pretendiendo la tuición), el tribunal consideró que "no se acreditó debidamente en autos una inhabilidad o causa calificada que le impida [a la madre] ejercer su rol, sin que obste a ello el supuesto bienestar general que el padre brindaba a los hijos en un entorno socioeconómico elevado”. Por tanto se desestimó el recurso de casación en el fondo interpuesto por el padre contra la sentencia de segunda instancia que confirma la de primera, que acoge la pretensión de la madre y desestima la del demandado. La Corte también consideró que, siendo el interés del niño un principio fundamental en el ordenamiento, no se advierte del mérito de autos que los sentenciadores de grado lo hayan preterido. Puede observarse que quien pretendía el cuidado personal de los hijos no aportó evidencia de motivos calificados que justificaran una modifi- 
cación de la atribución legal a la madre. En otras palabras, el demandante no logró convencer al tribunal de que el bienestar general que él podía proporcionar al niño satisfacía de mejor manera el interés superior de este que los cuidados de la madre. Por su parte, en Cazenave con Suazo (2004) se desestima la opinión de un niño que quería quedarse con el padre y la pretensión de este de tener la tuición del hijo. Nuevamente, no se prueba una causa calificada que haga indispensable una modificación de la tuición atribuida por ley a la madre. Además, aparece en autos que el padre no ha pagado pensiones alimenticias atrasadas, asunto que lo inhabilita ex ante para pretender el cuidado personal del niño (artículo 225 inciso $3^{\circ}, 2^{\mathrm{a}}$ parte).

En Toledo con Morales (2000), otro litigio promovido por la madre que pide la entrega inmediata de un hijo que, de facto, está en el hogar del padre, la Corte de Talca concede la tuición al padre porque ofrece "mejores condiciones integrales de vida" (una situación socioeconómica más mejorada que la de la madre). En este caso, a juicio del tribunal de alzada, "la regla que otorga preferencia a la madre para el cuidado de los hijos cede frente al interés superior del niño", criterio que el tribunal integra con las ventajas económicas que ofrecía el padre.

\section{B. El INTERÉS SUPERIOR DEL NIÑO COMO CRITERIO DE ATRIBUCiÓN JUDICIAL ENTRE PROGENITORES}

El interés superior del niño puede considerarse un principio vigente en la legislación chilena desde la incorporación al ordenamiento de la Convención sobre los Derechos del Niño ${ }^{47}$. La Ley 19.585 de 1998 incorpora el principio al Código Civil chileno (artículos 222 inciso $2^{\circ} ; 225$ inciso $3^{\circ} ; 242$ inciso $2^{\circ}$ ) y, con posterioridad a ella, el principio se expande a diversas piezas de legislación (especialmente, por ejemplo, al artículo 16 LTF).

La doctrina chilena ha hecho de este principio variados análisis desde perspectivas generales ${ }^{48}$. Podemos afirmar que el interés superior del niño es un principio que cumple diversas funciones. Es principio de política legislativa, gubernamental y, en general, administrativa (artículo 3 de la Convención sobre los Derechos del Niño). Es principio de política judicial (artículos 9 y 40 de la misma Convención). Pero, en el ámbito del cuidado personal de los hijos (artículo 225 inciso $3^{\circ}$ ) y del derecho a mantener con ellos una relación directa y regular (artículo 229 y artículo 9 de la Convención), el interés superior del niño es también un criterio, baremo o standard de adjudicación de litigios (artículo 242 inciso $2^{\circ}$, artículo 16 LTF). Esta última es la función que interesa en el contexto de estas líneas: el interés superior del niño como criterio de resolución de conflictos judiciales.

Comenzaré con las críticas que se suelen hacer de este standard. Luego, haré una propuesta de cómo debería funcionar este criterio para moderar la carga subjetiva y de arbitrariedad que se le atribuye.

\footnotetext{
47 GÓmez de la Torre (2000); BAeza (2001) pp. 23-26 y 344-362; Cillero (2003) pp. 51-70.

48 Tuición del menor Benjamín Cabral May (2004). Comentada por TURner SAELZER (2004) pp.273-278. Citada por GÓMEZ DE LA TORRE (2007) p. 139.
} 


\section{Crítica del principio como criterio de atribución judicial al otro progenitor}

Se acusa al interés del niño, como criterio de adjudicación, de ser un criterio indeterminado, vago, impreciso, vulnerable a la discreción judicial y difícil de satisfacer de forma imparcial, según el mérito del caso. Las limitaciones de esta función del principio son ampliamente admitidas por lo autores y la judicatura. Por ejemplo, antes de integrar el contenido que a juicio del tribunal había que darle al concepto, en una sentencia chilena reciente la redactora reconoció que "el interés del menor constituye un concepto jurídico indeterminado, de contornos imprecisos" ${ }^{49}$. Hay abundante literatura de la más variada procedencia y época que incide en este problema. Solo mencionaremos algunos estudios relevantes y citados.

En Estados Unidos, ya en 1975, la literatura criticaba el principio en la resolución de problemas de custodia (cuidado personal de los niños) por la excesiva discrecionalidad que entrega al juzgador: "[1]a determinación sobre qué es lo 'mejor' o 'menos malo' para un niño en particular es algo indeterminado y especulativo", escribía un autor ${ }^{50}$. "Puesto que lo que sea el interés superior para un niño en particular es indeterminado, hay buenas razones para estar preocupado por la extensión del poder [de discreción] que ejercitan los jueces en la resolución de problemas de tuición" ${ }^{51}$. Otro autor procedente de la academia criticaba el principio con las siguientes palabras: "Es el ejemplo más claro de la ineficacia de pretender una perfecta e individualizada justicia otorgando discrecionalidad al juez"52. En una opinión tal vez extrema, pero autorizada, en 1987 Jon Elster concluye que el interés superior del niño es tan indeterminado como criterio de adjudicación que más le vale al juez resolver "por cara o sello"; es decir, utilizar la suerte como regla de atribución. El azar -argumenta Elster- asegura la igualdad de padre y madre. Por tanto, parece no tener los inconvenientes que desde esta perspectiva tiene una presunción de idoneidad a favor de la madre o el criterio que adjudica los hijos al progenitor que los cuida de hecho. Este último criterio, además, ha dejado de ser relevante desde la plena incorporación de las mujeres al trabajo ${ }^{53}$.

Joseph Goldstein, Albert J. Solnit, Sonja Goldstein y Anna Freud, autores del estudio más citado de los últimos treinta años acerca del interés superior del niño, reconocen que en ausencia de una definición clara del concepto, cuestión no resuelta hasta hoy, las preferencias personales de los jueces pueden gobernar sus decisiones; y que cuando dos adultos compiten por la tuición de un niño, el interés superior del niño puede ser equivalente al interés del adulto que más lo merece ${ }^{54}$. En otras palabras, para estos autores, como criterio para la resolución de conflictos judiciales sobre cuidado personal de los hijos prevalecería una de las siguientes alternativas: la discrecionalidad judicial, el interés del padre o el interés de la madre.

\footnotetext{
${ }^{49}$ MNOOKIN (1975) p. 229.

50 MNOOKIN (1975) p. 230.

51 GLENDON (1986) p. 1181.

52 ELSTER (1987) p. 44.

53 GOLDSTEIN et al. (1996) xiii.

54 Rivero Hernández (2007) p. 64.
} 
Rivero Hernández ${ }^{55}$ hace eco de estas y otras numerosas críticas procedentes de las más amplias fuentes bibliográficas, tanto del mundo anglosajón como continental. El interés superior del niño como standard jurídico se caracteriza por su relatividad y por su dinamismo. Se trata de un concepto que depende demasiado de las coordenadas personales y circunstancias del caso; y además, es cambiante, evoluciona con el paso del tiempo ${ }^{56}$.

¿Cómo salir de la discrecionalidad que arriesga el interés del niño como concepto jurídico indeterminado?

La literatura norteamericana propone volver a reglas fijas, del estilo de nuestro artículo 225, pero buscando figuras que sean neutras desde el punto de vista del género. Los Principles of the Law of Family Dissolution (2002) proponen dividir los temas de cuidado personal en dos áreas: toma de decisiones y residencia de los niños. En el primer ámbito, los Principios proponen joint decision making (toma de decisiones conjunta); en el ámbito de la residencia, proponen la aproximation presumption (dividir el tiempo de residencia entre los padres según el tiempo que dedicaba cada uno al cuidado de los niños antes del divorcio) o la equal physical custody presumption (cuidado personal conjunto 50-50). Pero estas propuestas, hechas de lege ferenda por el American Law Institute, son resistidas por la academia y la práctica. La primera, porque no resuelve claramente qué materias son relevantes como para que exijan decisiones conjuntas. Si los padres viven separados, no pueden quedar todas las materias sujetas a decisión conjunta. Además, porque judicializa todos los desacuerdos entre los padres relativos a decisiones sobre los hijos. No es un criterio que favorezca la paz familiar.

El segundo sistema se critica porque se considera una "vuelta atrás" que favorecería a las mujeres. Y el tercero, porque exige verdaderamente mutuo acuerdo y cooperación entre los padres, lo cual está muy lejos de ocurrir en el contexto de un juicio ${ }^{57}$. Además, el estudio más citado en el último tiempo constata que, de hecho, aun en familias que han optado por igual distribución del tiempo, los niños pasan la mayor parte del tiempo con sus madres ${ }^{58}$.

Rivero Hernández intenta hacer operativo el principio con elementos procedentes del Derecho Administrativo, como parecen ser las normas que permiten la discrecionalidad de la administración ${ }^{59}$. En la estructura de estos conceptos, afirma el autor ${ }^{60}$, la doctrina distingue entre una zona de certeza positiva, configurada por unos datos seguros con que se satisface el concepto; una zona de certeza negativa en la cual desaparece por completo el valor incorpora-

\footnotetext{
55 RiVERO HERNÁNDEZ (2007) p. 70.

56 SCHEPARD (2004) pp. 162-174.

57 Maccoby y MnOOKIN (1992) pp. 112, 149-153; también citado por SCHEPARD (2004) nota 522 y texto que la acompaña.

58 RIVERO HERNÁNDEZ (2007) pp. 71-73.

59 Rivero Hernández (2007) pp. 72 y 73.

${ }^{60} \mathrm{Me}$ inspiro aquí en la estructura de las normas jurídico-administrativas indeterminadas que permiten la discrecionalidad de la administración. Sigo en esto a RIVERO HERNÁNDEZ (2007) p. 71. La construcción del funcionamiento de estas normas se atribuye al alemán Walter JELLINEK, quien la formula en su obra Gesetz, Gesetzesanwendung und Zweckam ssigkeitserw gung: Zugleich ein System der Ungültigkeitsgründe von Polizeiverordnungen und-verfügunden (Tubinga, 1913). Al respecto, BACIGALUPO (1997) pp. 193-217.
} 
do en el concepto (por ejemplo, deja de ser servido el interés del niño); y por una zona intermedia de variación e incertidumbre, donde caben opciones varias dentro de márgenes relativos e imprecisos. En el concepto jurídico impreciso, la ley no da la solución. Esta debe ser buscada por el juez acudiendo a juicios de experiencia o de valor que, a su vez, deben ser objeto de una valoración jurídica según el sentido que la ley ha dado al concepto indeterminado para el supuesto de hecho concreto. Corresponde al juez llenar de contenido efectivo el concepto indeterminado al juzgar y valorar el supuesto de hecho.

Ahora bien, discrecionalidad judicial no es arbitrariedad. La ley autoriza al juez a resolver discrecionalmente un caso, conforme a un criterio indeterminado, conforme a motivaciones y razonamientos. La resolución arbitraria es la decisión "porque quiero", que no es "razón", sino voluntad, deseo, capricho. Interesa destacar que el principio del interés superior del niño como criterio de atribución judicial del cuidado personal de niños y adolescentes es un criterio jurídico, es decir, exige motivos, fundamentos, razones que “justifiquen" la decisión que pretende ser “justa”. En otras palabras, exige resolver conforme a las reglas de la sana crítica de datos y circunstancias conforme a un criterio indeterminado. Es resolver discrecionalmente, no arbitrariamente.

\section{Funcionamiento del principio como regla de atribución}

Asumiendo las premisas expuestas anteriormente, interesa examinar el funcionamiento del principio del interés superior del niño como regla de atribución judicial del cuidado personal de niños y adolescentes en juicios entre sus progenitores. En el marco de la atribución judicial del cuidado personal de los hijos, el interés superior del niño es, efectivamente, un criterio jurídico indeterminado. Sin embargo, en el Derecho chileno opera como regla de escrutinio y atribución conforme a parámetros que orientan la decisión judicial y reducen los márgenes de discrecionalidad.

El razonamiento lógico que la ley exige al juez podría formularse de la siguiente forma: "Si los padres viven separados (supuesto de hecho determinado), a la madre toca el cuidado de los hijos (atribución legal determinada); en todo caso (escrutinio judicial de esta atribución) cuando el interés del hijo lo haga indispensable (criterio jurídico indeterminado), sea por maltrato, descuido u otra causa calificada (supuesto fáctico indeterminado), el cuidado personal del niño o adolescente debe pasar al otro de los padres".

El artículo 225 ofrece al juez un criterio fáctico determinado y una regla determinada, pero exige también al tribunal la integración de un supuesto fáctico indeterminado y de un criterio de atribución indeterminado. Este proceso de integración fáctico y normativo debería consistir en la subsunción de hechos y de juicios de experiencia y de valor en la norma, conforme a su ratio. Esta integración-interpretación teleológica es la operación lógica que el legislador exige al juzgador para conseguir la flexibilidad judicial que auspicia ${ }^{61}$.

61 Tuición del menor Benjamín Cabral May (2004). Considerando Sexto. El juicio se resuelve conforme al criterio del interés superior del niño, a pesar de que se trata de la pretensión de una tía del menor de que se le atribuya la tuición contra el padre, único progenitor vivo del niño, que no está en condiciones de cuidar a su hijo. En opinión de este estudio, este pleito debió haber sido resuelto conforme al artículo 226 y no conforme al artículo 225 . 
La discrecionalidad que la norma permite al juzgador radica, precisamente, en su obligación de integrar teleológicamente un supuesto fáctico y normativo indeterminado o incompleto. El tribunal no puede sustraerse de esta obligación que le exige ponderar razones de experiencia y juicios de valor en función de la finalidad de la regla de atribución "interés superior del niño". La decisión discrecional exige rigurosa fundamentación, expresión de motivos y respeto al marco legal y constitucional vigente. Son estos motivos los que quedarán sujetos a revisión y enmienda por los tribunales superiores, conforme a la ley (artículo 67 LTF).

A continuación revisaré algunos ejemplos de este proceso de integración-interpretación tomados de la jurisprudencia chilena reciente. En el marco de la Tuición del menor Benjamín Cabral May (2004), la Corte de Apelaciones de Santiago desarrolla un test de integración-satisfacción del interés del niño que consiste en la verificación en el supuesto de hecho de los siguientes antecedentes:

$\left.1^{\circ}\right)$ la probabilidad de que las necesidades materiales, educativas y emocionales del menor sean cubiertas o no por quien pide la tuición;

$2^{\circ}$ ) el solicitante de la tuición tiene o no capacidad y condiciones para asumir el cuidado personal del niño;

$3^{\circ}$ ) el efecto probable de cualquier cambio de situación en la vida actual del menor; y

$4^{\circ}$ ) el daño sufrido o riesgo de sufrirlo como consecuencia de la tuición ${ }^{62}$.

En Hernández con Sarmiento (2008), la Corte Suprema integra el supuesto fáctico "causa calificada" con la continuidad, estabilidad, protección y apego filial que la hija de nueve años parece tener en el hogar del padre, con quien de hecho vive desde el año 2004, lo que en función de su interés justifica que, acogiendo el recurso de casación presentado por el padre, el tribunal anule la sentencia de segunda instancia que revocó la de primer grado para que se conceda el cuidado personal al padre. El tribunal atribuyó también envergadura a la opinión de la niña, que manifestó su deseo de continuar viviendo con su padre. Ambos padres eran igualmente idóneos para tener el cuidado personal de su hija y no habían conseguido celebrar válidamente una convención sobre el cuidado personal de su hija. En función del interés de la niña, el máximo tribunal consideró que debía mantenerse el statu quo vigente. Se advierte aquí otro elemento para integrar el criterio "interés superior del niño": ¿hay ventajas para el niño o adolescente si se accede a la pretensión de uno de los padres (componente positivo)?; ¿’hay riesgos o perjuicios para el niño si se accede a esta pretensión (componente negativo)? La decisión debería complementar las mayores ventajas con las menores desventajas o riesgos de daño o perjuicio.

En Garrido con Lagos (2008), la Corte Suprema en definitiva deja a firme la decisión de los jueces de grado de acceder a la pretensión de la madre que pide la tuición

62 Garrido con Lagos (2008). Considerando Decimoséptimo del fallo de primera instancia. Cabe señalar que el fallo establece un régimen amplio de comunicación directa y regular a favor del padre. 
de un hijo contra el padre, que la tiene por convención celebrada anteriormente con ella. En una reconciliación entre los padres ha nacido otra hija que está bajo el cuidado de su madre. Los jueces de instancia determinan que ambos padres son igualmente idóneos para tener el cuidado de sus hijos. La separación obedece a situaciones de maltrato y violencia intrafamiliar contra la demandante, pero este factor no influye en el juicio de idoneidad que hacen los jueces de ambos progenitores para el cuidado de sus hijos. Curiosamente en este juicio no se acreditó por la parte demandante (la madre) "maltrato, descuido u otra causa calificada" que justificara una modificación de la atribución convencional previa. Se desatendió la opinión del niño de diez años que deseaba permanecer en el hogar de su padre, bajo el cuidado de su abuela paterna.

El juez de familia falló a favor de la madre:

"La distribución de los hijos entre los padres [...] que permite el artículo 225 es una circunstancia que solo puede justificarse en el interés de los propios hijos, pero cesando la causa que la originó, no se ve inconveniente para volver las cosas al estado anterior, es más, la intervención judicial debe instar, en la medida de lo posible, para volver las cosas a su estado natural, velando entre otros aspectos, por la no separación de los hermanos máximo [sic] cuando ya se ha sufrido el dolor de ver a sus progenitores separados, añadido que, cuando esta madre tomó la decisión de entregar el cuidado de su hijo, es claro que hubo una suerte de fuerza moral que la determinó a ello" 63 .

En otras palabras, el juez de familia integra el principio "interés superior del niño" con el beneficio que para el niño se seguiría de la vida con su hermana y su madre, todos unidos como familia. La Corte de Temuco hace suyos estos razonamientos al confirmar la sentencia. La Corte Suprema desestima el recurso de casación deducido por el padre, considerando que la manera como fue resuelto el juicio no ofende el principio del interés superior del niño (Considerando Séptimo de fallo del tribunal de casación.)

En Estados Unidos, diversas legislaturas han adoptado tests de satisfacción del interés superior del niño, como el del Estado de Minnesota:

"El interés superior del niño significa todos los factores relevantes que deben ser evaluados por el tribunal, incluyendo: 1) los deseos del niño y sus padres en relación a la tuición; 2) las preferencias razonables del niño, si se considera que tiene la suficiente madurez para expresar una preferencia; 3) quién ha cuidado al niño hasta ahora; 4) la intimidad que tiene la relación de cada uno de los padres con el niño; 5) la forma en que el niño interactúa y se relaciona con su padre o madre, u otros parientes que pueden afectar significativamente su vida; 6) la adaptación del niño en su hogar, en su escuela y en su comunidad; 7) el tiempo que el niño ha vivido en un ambiente estable y satisfactorio y el interés en mantener una continuidad en su vida; 8) la estabilidad, como familia, que podría

63 Minnesota Annotated Statutes (2002) $\$ 518.17$ (traducción libre de la autora). 
proporcionarle el progenitor que tiene o pide la tuición; 9) la salud física y mental de todas las personas envueltas en el juicio; 10) la capacidad o decisión de las partes de proporcionar al niño cariño y dirección, y continuidad en la crianza y educación del niño conforme a sus creencias religiosas y/o culturales; 11) el ambiente cultural del niño; 12) el efecto que ha tenido en el niño cualquier forma de maltrato intrafamiliar.

El juez puede no usar solo uno de estos factores, excluyendo todos los demás. No puede entregar el cuidado personal a quien ha cuidado al niño, solo por esta razón. Debe fundamentar cuidadosamente su decisión haciendo referencia a cada uno de estos factores, y explicar como todo esto satisface el principio del interés superior del niño" 64 .

La cuestión de fondo que pretenden los tests de esta especie es proporcionar al juez elementos de juicio para fundamentar sus decisiones discrecionales con argumentos de relevancia jurídica.

Como contrapunto, podemos comparar todos estos razonamientos con el que debe realizar el tribunal para atribuir el cuidado personal a terceros, parientes o extraños, separando al niño de sus padres biológicos. Como señala el artículo 226, "en el caso de inhabilidad física o moral de ambos padres [nuevamente, un supuesto fáctico indeterminado], podrá el juez confiar el cuidado personal de los hijos a otra u otras personas competentes, debiendo preferir a los consanguíneos de grado más próximo y sobre todo a los ascendientes [consecuencia jurídica determinada, con opciones señaladas por el legislador]". En este caso, el supuesto fáctico indeterminado "inhabilidad de ambos padres” está integrado por el artículo 42 de la Ley de Menores, que proporciona al tribunal una relación de hechos que determina parcialmente el supuesto. Esto no ocurre con la regla del artículo 225 inciso $3^{\circ}$, puesto que tanto el supuesto fáctico "maltrato, descuido u otra causa calificada" como el criterio para atribuir la consecuencia jurídica que consiste en el cambio del cuidado personal al otro progenitor, el "interés del hijo", están indeterminados ${ }^{65}$.

\section{Caso especial de la homosexualidad. El Caso lópez con Atala (2004)}

El caso Atala (López con Atala [2004]) ha sido objeto de numerosos comentarios, pues despertó en su momento y sigue provocando aguda polémica ${ }^{66}$. En este artículo

\footnotetext{
${ }^{64}$ No obstante, las opciones del juez están determinadas y son bastante más restringidas que las que la ley ofrece en el artículo 226. Estas son, como hemos dicho: el padre o la madre. En otras palabras: la sentencia solo puede ser estimativa (acogiendo la pretensión del progenitor que pide la tuición) o desestimativa (negando lugar a esta pretensión).

65 Sólo por mencionar comentarios publicados en revistas o escritos académicos: NAVARRO BELTRÁN (2004); Donoso Rodríguez (2004); TOlEdo VÁsQuez (2005); SCAla (2005). Comentan especialmente el fallo de la Corte Suprema: BAEZA y NAVARRo (2004). A estos debe agregarse: Vial DE AMESTI (2007) quien analiza cuidadosamente las opiniones de los defensores y adversarios del fallo de la Corte Suprema.

${ }^{66}$ Sobre este tema, VIAL DE AMESTI (2007) pp. 49-80.
} 
interesa examinar el caso desde la perspectiva de la convivencia lésbica iniciada por la madre (hechos que se pretenden subsumir en el supuesto indeterminado "causa calificada”) y el interés del niño como criterio de atribución judicial (indeterminado) del cuidado personal de los hijos.

\section{La homosexualidad activa como factor de integración de una causa calificada 67}

Las conductas homosexuales activas de los padres que conviven con sus hijos continúan siendo materia de polémica y no parece prudente descartarlas a priori como motivo calificado que justifique una modificación del cuidado personal, en función del interés de los niños ${ }^{68}$.

El argumento de este estudio es que hay que respetar la libertad de los jueces de examinar el caso concreto en función del interés del niño, atribuyendo el cuidado personal a aquel de los progenitores que ofrezca servir de mejor manera el interés superior del niño.

No podemos permitir que los jueces puedan verse perturbados en su labor de discernimiento del mayor bien o bienestar posible para los niños por el argumento que sugiere que todo fallo contrario a los intereses colectivos de minorías sexuales es discriminatorio, porque el Estado y la judicatura deberían ser neutrales ${ }^{69}$. Este argumento no se sostiene porque el Estado y la judicatura no pueden ser neutrales. Todo el ordenamiento reconoce el valor de determinados bienes (la persona humana, la vida, las libertades fundamentales, la familia) y sanciona, siquiera moralmente, determinados males (homicidio, lesiones, privación arbitraria de libertad, tortura, daños a la propiedad, etcétera).

La homosexualidad activa del padre o de la madre que conviven con sus hijos menores de edad no tiene sanción; efectivamente, no es un crimen. Sin embargo, es inevitable, y no podría dejar de ser así, que la judicatura pondere el modo de vida de los progenitores conforme a criterios valóricos al momento de formarse un juicio sobre el hogar que mejor sirve al interés del niño: el del padre o el de la madre. Por tanto, en su labor de integración de supuestos fácticos y normativos indeterminados e incompletos, como los que contiene el artículo 225 inciso $3^{\circ}$, los jueces deben ponderar los mayores bienes que en el caso concreto satisfacen el interés de los niños. En esta labor es inevitable que hagan juicios éticos. Deben hacerlo porque el legislador les impone esta obligación cuando evita opciones determinadas y favorece la flexibilidad que permiten los

\footnotetext{
67 En el contexto de la casuística norteamericana son bastante relevantes dos trabajos: SHAPIRO (1996), quien critica la jurisprudencia que niega la custodia de niños a padres homosexuales, y WARDLE (1997), quien aporta argumentos que respaldan la tendencia de negar la custodia de niños a padres homosexuales. Aunque pueden citarse casos en todos los sentidos posibles, según GILL (2001), a la fecha en que escribe los tribunales seguían negando la custodia de niños a homosexuales y lesbianas. Esta literatura demuestra que la homosexualidad activa continúa siendo un factor polémico en los juicios sobre atribución del cuidado personal de los hijos.

68 Argumentan en este sentido, por ejemplo, Ruiz-TAgle (2004) y Toledo (2005).

${ }^{69}$ Informe $N^{\circ}$ 42/08. Admisibilidad. Petición 1271-04. Karen Atala e hijas. Chile.
} 
criterios judiciales discrecionales, como el del interés superior del niño. Nadie puede ignorar que esta fue precisamente la opción de la legislatura que adoptó la Ley 19.585 de 1998.

Por eso, cuando los jueces eligen entre dos opciones la que mejor satisface el interés del niño, sin fallar automáticamente por opciones hechas a priori por la ley (por ejemplo, en el supuesto del artículo 225 inciso $1^{\circ}$ ), no discriminan en un sentido "discriminatorio", sino que realizan una labor para la que la legislación les proporciona discreción y flexibilidad. Elegir lo que a juicio del juzgador parece un bien para el niño significa discriminar o distinguir entre varias opciones posible. Esta "discriminación” no es arbitraria o injusta. De hecho, en todo juicio de tuición, los jueces discriminan entre el padre y la madre, para adjudicar el cuidado personal a uno u otro y no por ello debe calificarse esta labor de "discriminatoria" por sexo u opción sexual. A lo largo de estas páginas hemos revisado los innumerables argumentos que desacreditan criterios que han buscado neutralidad, sin conseguirlo.

\section{Los hechos y el desenvolvimiento procesal del caso López con Atala (2004)}

En apretada síntesis, los hechos son los siguientes. El padre de tres niñas que se encuentran bajo el cuidado personal de su madre, por convención entre los progenitores al momento de su separación, pide la tuición de las menores. Como supuesto fáctico que justifica la intervención judicial y modificación de la tuición, el demandante invoca la convivencia lésbica que la madre ha iniciado con otra mujer en el hogar donde vive con las niñas. La madre se defiende alegando que su opción de vida no la inhabilita para tener el cuidado de sus hijas. Provisionalmente, y mientras se tramita el juicio, el juez de letras atribuye el cuidado de las niñas al padre. Las partes agregan al juicio gran cantidad de literatura procedente del campo de la psicología, la psiquiatría y sociología, como asimismo opiniones de peritos y testigos como evidencia que apoya la posición de una y de otra.

En primera instancia, la jueza subrogante del Juzgado de Villarrica, donde se tramita el juicio, desestima la pretensión del demandante. Esta sentencia es confirmada por unanimidad en la Corte de Apelaciones de Temuco. El caso llega a la Corte Suprema por vía de un recurso (disciplinario) de queja que deduce el demandado contra los ministros y el fiscal de la Corte de Apelaciones de Temuco, por falta o abuso en el desempeño de sus deberes. La Corte acoge el recurso e invalida las sentencias de grado declarando que se concede al demandante la tuición de sus hijas menores, haciéndose lugar a la demanda (voto de mayoría de los ministros José Luis Pérez, Urbano Marín y Jorge Rodríguez).

Con motivo de esta sentencia, el 24 de noviembre de 2004 la señora Atala deduce una denuncia contra el Estado de Chile por violación de derechos garantizados por la Convención Americana de Derechos Humanos ante la Comisión Interamericana de Derechos Humanos, la cual es declarada admisible el 23 de julio de $2008^{70}$.

\footnotetext{
${ }^{70}$ Considerando Trigésimo noveno de la sentencia del Juzgado de Letras de Villarrica.
} 


\section{Interés superior del niño versus inhabilidad de la madre}

El caso Atala es una muestra muy significativa de la tensión que hemos observado entre la integración del criterio del interés del niño y del supuesto fáctico que establece el artículo 225 (en este caso, "causa calificada"). El problema más importante que toca decidir a los tribunales en este caso es si la convivencia lésbica de la madre con una compañera sentimental constituye o no "causa calificada" para modificar judicialmente la convención sobre cuidado personal de sus tres hijas. Conjuntamente con esta decisión, los tribunales también se ven obligados a considerar si el interés superior de las niñas (o el mejor interés de las niñas) es satisfactoriamente servido en el hogar de la madre y si el cambio experimentado en las circunstancias del hogar materno acaso aconseja también un cambio en la tuición de sus hijas. Es decir, la situación fáctica ¿justifica la intervención judicial? Resuelta positivamente esta cuestión, estos mismos hechos ¿̇integran el supuesto fáctico "causa calificada"? Finalmente, la atribución judicial del cuidado personal de las niñas al padre, ¿sirve de mejor manera el criterio de adjudicación legal "interés superior del niño" o no? A mi juicio, estas son las preguntas que deberían haber buscado respuesta en la decisión de la litis.

Sin embargo, los fundamentos de la sentencia de primera instancia (a cargo de la jueza subrogante del Juzgado de Letras de Villarrica, Viviana Cárdenas Beltrán) discurren casi exclusivamente sobre una cuestión ajena a lo anteriormente indicado. En efecto, el Juzgado de Letras de Villarrica decide el juicio en función de la falta de inhabilidad de la madre para tener la tuición de sus hijas: "No existe ninguna causa legal que inhabilite a [la demandada] para tener el cuidado personal de sus hijas menores, razón por la cual la demanda será rechazada" 71 . Es decir, a juicio del tribunal, la convivencia homosexual de la madre con su compañera sentimental en el hogar donde vive con sus hijas no constituye causa legal que la inhabilite para tener la tuición de sus hijas.

Efectivamente, puestas así las cosas, el artículo 42 de la Ley de Menores, norma invocada expresamente por el tribunal, no ofrece expresamente el supuesto "convivencia homosexual" en la nómina de causas de inhabilidad. Pero es que no correspondía decidir este juicio conforme a una regla de inhabilidad de la madre, ni menos, acudir al artículo 42 de la Ley de Menores, norma que sirve para discernir la inhabilidad de ambos padres para que la tuición pase a manos de terceros, parientes o extraños. A mi juicio, el tribunal yerra al vincular el artículo 225 inciso $3^{\circ}$-regla que debía decidir la litis- con el artículo 42 de la Ley de Menores, que no correspondía invocar ni ponderar en este juicio.

El tribunal yerra también al desestimar la envergadura del principio del interés superior del niño, al que dedica solo uno (el Considerando Vigésimo séptimo) de los cuarenta párrafos en los que pondera la prueba y las reglas conforme a las cuales debe decidir el juicio. El tribunal ni siquiera invoca el artículo 242 inciso $2^{\circ}$, norma que lo obliga a atender, como consideración primordial, el interés superior del hijo para adoptar sus resoluciones.

${ }^{71}$ También defienden la aplicación directa del principio del interés superior del niño: BAEZA y NAVARRO (2004) pp. 577-581. 
Para apreciar el verdadero valor que el tribunal atribuye a este principio podemos examinar las consideraciones que hace para descartarlo como criterio decisorio de la litis. El tribunal afirma que este principio (10) "no es un derecho por sí solo"; $\left(2^{\circ}\right)$ no es una "norma para aplicar en forma directa"; y (30) específicamente, que el principio debe aplicarse frente a una colisión de derechos de distinta jerarquía, cuyo ejercicio simultáneo resulte incompatible; como el derecho a la vida, a la integridad física o psíquica, a no ser separado de sus padres, a la identidad, y a la no discriminación, derechos que deben protegerse y privilegiarse cuando entren en conflicto con otros de menor jerarquía. Como en el caso, razona el tribunal, "no se ha acreditado que la madre de las menores haya puesto en peligro el respeto de los referidos derechos [de más alta jerarquía], por lo que, en concepto de esta sentenciadora, el principio del interés superior del niño no ha sido vulnerado" (Considerando Vigésimo séptimo).

Vamos por partes. $\left(1^{\circ}\right)$ Es equivocado afirmar que el interés superior del niño sea un derecho subjetivo. El principio, en el ámbito de las decisiones judiciales, es un criterio de adjudicación, como efectivamente especifica el artículo 242 inciso $2^{\circ}$ y el artículo $3^{\circ}$ párrafo 1 de la Convención de Derechos del Niño: una consideración primordial a la que se atenderá es el interés superior del niño.

(2o) Esta constatación destruye el segundo de los argumentos del juzgado de primera instancia: que el principio no tiene aplicación directa. Debe tenerla y de hecho la ha tenido en numerosos casos antes y después de la reforma efectuada por la Ley 19.585 de 1998. Entre otros, pueden citarse los siguientes casos que deberían haber inspirado esta aplicación directa que el juzgado estima improcedente: Tuición del menor Vicente Ibáñez Guzmán (1989) (el tribunal invoca el principio del interés del niño para negar tuición a la madre natural); Tuición de Maribel del Carmen Oróstica (1996) (aplicación directa de la Convención de Derechos del Niño para desestimar una demanda de tuición); Molina con Orellana (1997) (aplicación directa de la Convención de Derechos del Niño para desestimar la demanda del padre que pide ampliación de un régimen de visitas); Zuloaga con Escobar (2002) (restitución internacional denegada por aplicación directa del interés superior del niño $)^{72}$.

(3o) Como principio decisorio en el caso de colisión de derechos fundamentales de distinta jerarquía, el interés superior del niño opera en otras materias. No corresponde invocar esta función del principio en un juicio en que los padres de unas niñas disputan sobre su tuición. En estos juicios no se discute la colisión de derechos fundamentales. Por tanto, cuando el tribunal utiliza este principio como dirimente de una supuesta colisión yerra y hace una equivocada aplicación de un criterio de adjudicación que debió haber ponderado como criterio fundamental para decidir el juicio. El interés de las niñas efectivamente sale vulnerado si el litigio sobre su tuición se decide con criterios que ponderan la aptitud o ineptitud de la madre y no el interés de las niñas.

A pesar de estos graves defectos, la sentencia de primera instancia fue confirmada en alzada por la Corte de Apelaciones de Temuco, por unanimidad. Contra esta decisión, el demandante recurre al máximo tribunal alegando falta o abuso en los ministros

\footnotetext{
${ }^{72}$ Considerando Décimo noveno, énfasis agregado.
} 
del tribunal de alzada y demás sentenciadores al no haber ponderado debidamente los hechos ni el derecho aplicable al litigio. La Corte Suprema, conociendo de este recurso, e invocando el principio del interés superior de las niñas como decisorio del caso, invalida las sentencias de grado, dando la tuición de las niñas a su padre.

A juicio del voto de mayoría de la Corte Suprema (ministros señores José Luis Pérez, Urbano Marín y Jorge Rodríguez), las sentencias de grado deberían haber ponderado la "causa calificada" que invocaba el demandante (el inicio de una convivencia homosexual entre la madre y una pareja de su mismo sexo) sin descansar demasiado en las opiniones especializadas, sino en los testimonios que permitían constatar el deterioro de la vida de las niñas desde que ocurre el hecho que motiva el juicio. Todos estos antecedentes "configuran un cuadro que irroga el riesgo de daños [a las niñas], lo[s] que podrían tornarse irreversibles para las menores cuya protección debe preferir a toda otra consideración, en los términos definidos imperativamente por la normativa que gobierna la materia"73. Mantener la atribución hecha por los jueces de grado a la madre suponía, a juicio del máximo tribunal, un riesgo lo suficientemente serio como para intervenir acogiendo la pretensión del padre.

\section{El argumento de los derechos fundamentales}

El voto de minoría de la sentencia de la Corte Suprema (ministros señores José Benquis y Orlando Álvarez), entre otras razones de orden procesal, se opone al de mayoría por una supuesta discriminación en contra de la madre, que el fallo haría suya:

"Restarle a la madre, solo por su opción sexual, la tuición de sus hijas menores de edad -como lo ha requerido el padre sobre la base de apreciaciones netamente subjetivas- involucra imponer tanto a aquellas como a la madre una sanción innominada y al margen de la ley, amén de discriminatoria"74.

La opinión se apoya, como puede leerse en el fundamento octavo del mismo voto, en las causas legales de inhabilidad del artículo 42 de la Ley de Menores, con relación al artículo 226. Nuevamente, y esta vez por ministros de la más alta magistratura de la República, se incurre en un error sobre la regla decisoria del juicio, que no es el artículo 226 en relación al artículo 42 de la Ley de Menores, sino el artículo 225 inciso $3^{\circ}$ en relación al artículo 242 inciso $2^{\circ}$. Es decir, la regla decisoria del juicio era el principio del interés superior del niño, el cual, a juicio de la mayoría, se encontraba mejor servido si las niñas vivían en el hogar de su padre que en el de su madre.

Algunos autores han levantado las siguientes críticas al fallo de la Corte Suprema:

(10) Que "recoge la discriminación social existente en nuestra sociedad en contra de las personas homosexuales como un argumento más a favor de negar la tuición a la madre" 75 .

73 Considerando Noveno del voto de minoría.

74 TOledo VÁsquez (2005) p. 148.

75 Vial Ruiz-TAGLe (2004) p. 430. 
(20) Que tampoco ha tenido en cuenta el interés de las niñas "al discriminar a su propia madre por razón de su homosexualidad" 76 .

Y, por último, $\left(3^{\circ}\right)$ que "la Corte Suprema ha fallado en una decisión que no puede revocarse"77.

Brevemente, me haré cargo de estas críticas para demostrar que no parecen tener suficiente fundamento:

$1^{\circ} \mathrm{Al}$ resolver como lo hizo, la Corte Suprema integró el criterio jurídico indeterminado “interés superior del niño" con juicios de valor legítimamente formulados y fundamentados en prueba rendida en el juicio. Al hacerlo, el tribunal ejercitó el derecho que le confiere el legislador al ofrecer como criterio o baremo de adjudicación un concepto jurídico indeterminado. Hizo lo que debieron haber hecho los jueces de grado.

La acusación de haberse hecho eco el tribunal de prejuicios podría formularse contra cualquier juez que decide haciendo uso de facultades discrecionales que le proporciona la ley. En concreto, esta forma de resolver también podría haber sido la de los jueces de grado: en primera instancia, los sentenciadores podrían haber fallado a favor de la madre con fundamento en el artículo 225 inciso $3^{\circ}$, argumentando que la convivencia homosexual de la madre no constituía "causa calificada" que justificara la atribución judicial del cuidado personal de las niñas al padre. En segunda instancia, la Corte de Temuco podría haber hecho suyo este razonamiento confirmando el fallo sometido a su revisión. Pero los jueces de grado aplicaron reglas improcedentes (artículo 226 en relación al artículo 42 de la Ley de Menores) a las circunstancias fácticas que motivaron el juicio (artículo 225 inciso $3^{\circ}$ ). Fallaron a favor de la madre por consideraciones que se apartaban del interés superior del niño, "consideración primordial" (artículo 242) a la que debieron haber atendido.

$2^{\circ} \mathrm{La}$ integración del principio "interés superior del niño" por parte de la Corte Suprema con argumentos de experiencia y juicios de valor no constituye discriminación arbitraria. En efecto, como hemos visto a lo largo de este estudio, la integración finalista del criterio "interés superior del niño" es un proceso legítimo de resolución judicial conforme a un criterio jurídico indeterminado. La decisión discrecional de la judicatura no es una decisión arbitraria. La Constitución prohíbe toda discriminación arbitraria. Las leyes que establecen distinciones en función del sexo no son arbitrarias. Tampoco puede acusarse a los jueces de arbitrariedad cuando hacen uso de facultades discrecionales, por muy criticables que estas sean en sí mismas.

$3^{\circ}$ Las decisiones sobre cuidado personal de los hijos pueden modificarse siempre que se acrediten hechos que justifiquen una nueva intervención y decisión judicial. Estas sentencias solo producen cosa juzgada formal, lo que permite a las partes volver a

\footnotetext{
76 Vial Ruiz-TAGLE (2004) p. 432.

77 Efectivamente, en virtud de un cambio de circunstancias, los tribunales pueden volver a conocer de un litigio entre los padres sobre el cuidado personal de sus hijos. Así lo ha declarado la Corte Suprema en Duarte con Olivares (1946) (se modifica atribución anterior a petición de la madre por cambio en las circunstancias) y, más recientemente, reiterando en dicta la misma doctrina, Di Pede con Silva (2008). En el ámbito de la doctrina procesal, Romero SEguel (2002) p. 30. Con anterioridad, dedica al tema una monografía PEREIRA ANABALÓN (1954).
} 
discutir la misma materia en un nuevo juicio, pues lo que en ellas se ha resuelto lleva implícita la cláusula 'mientras se mantengan las circunstancias' ${ }^{78}$. En este sentido, también ha errado la Comisión Interamericana de Derechos Humanos al declarar admisible la reclamación de la parte afectada contra una sentencia que produce cosa juzgada formal, pues, aunque no caben recursos contra ella, la materia puede volver a someterse a un juicio de la jurisdicción ordinario, entre las mismas partes. Por último, no hay ninguna razón para estimar que la sentencia de la Corte Suprema constituya precedente de una nueva decisión en el caso, si la peticionaria ofrece antecedentes que justifiquen un cambio en la atribución del cuidado personal de sus hijas en función del interés de las niñas ${ }^{79}$.

\section{LA INHABILIDAD DE LOS PADRES COMO CRITERIO DE ATRIBUCIÓN JUDICIAL A TERCEROS PARIENTES O EXTRAÑOS}

La inhabilidad del padre y de la madre supervive como regla de atribución de la tuición, pero solamente cuando se discute su adjudicación a terceros (artículo 226 en relación al artículo 42 de la Ley de Menores). El supuesto es que un tercero, pariente o extraño (como legitimado activo), pida al tribunal la adjudicación del cuidado personal de un niño, niña o adolescente contra el padre o madre que la tiene (legitimado pasivo). Para que obtenga su pretensión en este supuesto la ley exige la prueba de inhabilidad física o moral de ambos padres. Se requiere la prueba de inhabilidad no solo del padre o madre que tiene la tuición, sino de ambos padres, aunque no vivan juntos. De ser hábil, el otro de los padres prefiere frente a parientes de grado más lejano o terceros. Parece evidente que esto es así cuando la ley pide la inhabilidad física o moral de "ambos padres".

Acreditada la inhabilidad física o moral de ambos padres, la regla exige que el juez prefiera a los parientes consanguíneos más próximos para atribuir la tuición y, de entre estos, a los ascendientes (abuelos). Entre varias personas igualmente hábiles y llamadas en el mismo grado, el juez debe preferir a la más idónea, según el interés del niño (antiguo artículo 242). El caso más ilustrativo de la jurisprudencia reciente es Lincopil con Gómez (2008). El padre pretende el cuidado personal de su hija contra una tía materna que la tiene provisoriamente por atribución judicial. La demandada demuestra que el demandante está inhabilitado para cuidar de su hija por abusos sexuales a los que la habría sometido mientras estaba de visita en su casa. Estos abusos no fueron suficientemente comprobados en sede criminal. Sin embargo, de acuerdo a las reglas de la lógica y a máximas de experiencia, apreciando antecedentes que obran en el proceso, el tribunal de casación determina que la niña ha sufrido un maltrato grave, que inhabilita al padre, de acuerdo al artículo 226 en relación al artículo 42 de la Ley de Menores, para tener el cuidado personal de su hija. Las mismas razones llevan al tribunal a suspender el

78 Comisión Interamericana de Derechos Humanos, Informe No 42/08 de 23 de julio de 2008, sobre admisibilidad de la Petición 1271-04 formulada por Karen Atala e hijas contra el Estado de Chile.

${ }^{79}$ Los padres obtienen un régimen de comunicación amplio que les permite tener a la niña consigo todos los fines de semana y en todos los períodos de vacaciones escolares del año. Cf. parte resolutiva del fallo de segunda instancia. Tuición de la menor Kassandra Arriola Donoso (2008). 
derecho deber de tener con ella una relación directa y regular, hasta que nuevos antecedentes aconsejen lo contrario "para el desarrollo integral de la niña".

Este supuesto, que claramente es diferente a los del artículo 225, pide un juicio entre terceros (parientes o extraños) y uno o ambos padres. Exige que quien pretende que se le atribuya el cuidado personal acredite inhabilidad de los padres, conforme al artículo 226 y artículo 42 de la Ley de Menores. Sin embargo, igualmente exige al tribunal ponderar todos estos antecedentes en función del interés superior del niño (artículo 16 LTF). Así aparece claramente resuelto en Tuición de la menor Kassandra Arriola Donoso (2008), en lo que, a juicio de este estudio, es una clara tendencia de la jurisprudencia chilena. Los hechos son los siguientes: los padres viven juntos en Cartagena y piden el cuidado personal de su hija contra la abuela paterna que la tiene por haberle sido confiada por ellos en el año 2001, en un momento de gran precariedad económica, cuando se fueron a trabajar a un circo. En el juicio no hay antecedentes que acrediten la inhabilidad de los padres. La madre fue condenada anteriormente en un juicio de violencia intrafamiliar por agresión física a la abuela y a su hija, pero el tribunal no considera que este hecho la inhabilite para tener el cuidado personal de su hija. En primera instancia, se acoge la demanda. La Corte de Valparaíso, revoca. La Corte Suprema rechaza el recurso de casación en el fondo interpuesto por los demandantes. Tanto el tribunal de alzada como el de casación consideran que, si bien los padres no están inhabilitados para tener la tuición de su hija, en función del interés superior del niño (artículo 16 LTF), los jueces pueden modificar las reglas de atribución legal. Que este es el caso de la menor Arriola Donoso, que se encuentra incorporada y tiene estabilidad en el hogar de su abuela paterna. Las ventajas de que vuelva con sus padres no superan las desventajas que se seguirían para ella de abandonar el hogar de su abuela ${ }^{80}$.

\section{CONCLUSIONES}

El núcleo argumental de este estudio puede recapitularse en las siguientes proposiciones: el Derecho chileno favorece los pactos o convenciones entre el padre y la madre como forma preferente de atribución del cuidado personal de sus hijos, durante su vida separada. Esto significa un ámbito regulado de autonomía de la voluntad en estas decisiones y sus límites son formales y materiales. En cuanto a su forma, los pactos solo son admisibles por consentimiento del padre y de la madre dado en forma legal (por escritura pública o acuerdo escrito otorgado ante un oficial del Registro Civil, o por escrito aprobado por el juez que conoce de un proceso de separación, nulidad o divorcio). Los límites materiales de estos acuerdos se refieren al contenido.

A falta de acuerdo, la ley chilena opta por hacer una atribución automática y supletoria del cuidado personal a la madre. La subsistencia de esta regla de atribución

\footnotetext{
${ }^{80}$ Los padres obtienen un régimen de comunicación amplio que les permite tener a la niña consigo todos los fines de semana y en todos los períodos de vacaciones escolares del año. Cf. Parte resolutiva del fallo de segunda instancia. Tuición de la menor Kassandra Arriola Donoso (2008).
} 
legal automática y supletoria, es decir, que opera a falta de una convención entre progenitores, se justifica en el propósito de favorecer la solución extrajudicial de los conflictos mediante incentivos adecuados para que operen los acuerdos. La preferencia materna es la opción de política legislativa actualmente vigente en Chile, pero no excluye otras opciones legislativas, como la preferencia paterna según la edad y sexo de los hijos o la preferencia paterna incluso desde la infancia de los hijos. Es la existencia de la regla de atribución automática y legal lo que constituye el beneficio y el incentivo para la formación de acuerdos pacíficos sobre el cuidado personal de niños y adolescentes.

Los conflictos judiciales entre el padre y la madre sobre el cuidado personal de niños y adolescentes, por tanto, solo llegarían a materializarse si fallan los acuerdos o, con posterioridad, estos no resultan satisfactorios, o bien, si a falta de acuerdo, la atribución legal a la madre resulta inconveniente para el niño o adolescente en función de su interés, por maltrato, descuido u otra causa calificada. La inhabilidad de la madre o del padre, o de ambos, solo adquiere relevancia como criterio judicial de atribución del cuidado personal de niños y adolescentes a terceros, sean estos parientes o no. Es en estos juicios donde el tercero pariente o extraño reclama la tuición para sí, en los que debe producir prueba de la inhabilidad física o moral de ambos padres. Es una conclusión de este estudio que el criterio de inhabilidad de la madre o del padre no debe privilegiarse en juicios entre los progenitores, sino el interés del niño o adolescente. En cambio, en juicios entre el padre o la madre o ambos y terceros, el criterio que debe seguir el juez para privar del cuidado personal de niños o adolescentes a sus padres biológicos para entregarlo a un tercero, pariente o extraño, debe ser la inhabilidad de ambos padres, o del padre o madre sobreviviente, o del padre o madre que haya reconocido al hijo y lo tenga consigo.

\section{BIBLIOGRAFÍA CITADA}

Alascio Carrasco, Laura y Marín García, Ignacio (2007): “Juntos pero no revueltos: la custodia compartida en el nuevo art. 92 CC. La reforma del art. 92 por la Ley 15/2005, de 8 de julio", InDret Revista para el Análisis del Derecho (Barcelona, España), vol. 3: 23 pp.

AmAto, Paul R. (2002): "Good Enough Marriages. Parental Discord, Divorce, Divorce and Children's Long-Term Well-Being”, Virginia Journal of Social Policy and the Law, vol. 9, pp. 71-94.

Ascencio Hernández, Alicia (2000): El cuidado de los hijos en la familia disociada. Criterios de atribución (Memoria para optar al grado de licenciada en Derecho, Universidad Adolfo Ibáñez, dirigida por Fabián Elorriaga de Bonis) 345 pp.

BACIGALUPO, Mariano (1997): La discrecionalidad administrativa. Estructura normativa, control judicial y limites constitucionales de su atribución (Madrid, Marcial Pons) 338 pp.

BAEZA ConCHA, Gloria (2001): "El interés superior del niño: derecho de rango constitucional, su recepción en la legislación nacional y aplicación en la jurisprudencia”, Revista Chilena de Derecho, vol. 28 N$^{\circ}$ 2: pp. 355-362. 
Baeza Concha, Gloria y Navarro Galaz, Marco Antonio (2004): "Derecho de los menores a vivir en una familia normalmente constituida. Comentario al fallo de la Excma. Corte Suprema de 31 de mayo de 2004", Revista Chilena de Derecho, vol. 31 $\mathrm{N}^{\circ} 3$ : pp. 575-592.

BARROS BOURIE, Enrique (1999): "Notas históricas y comparadas sobre el nuevo ordenamiento legal de la filiación", El nuevo estatuto de filiación en el Código Civil chileno (Santiago, Fundación Facultad de Derecho Universidad de Chile) pp. 39-56.

Blockman, Arnold F. (2007): "Survey of Illinois Law: Joint Custody Dilemmas and Views From the Bench", Southern Illinois University Law Journal, vol. 31: pp. 941966.

Cillero Bruñol, Miguel (2003): "El interés superior del niño en la Convención Internacional sobre los Derechos del Niño: función y contenido", Revista de Derecho de la Universidad Católica de Temuco N IV: pp. 51-70.

Cochran, Robert F., Jr. y VITZ, Paul C. (1983): "Child Protective Divorce Laws: A Response to the Effects of Separation on Children", Family Law Quarterly, vol. 17: p. 327.

Court Murasso, Eduardo (2000): Nueva Ley de filiación (Santiago, ConoSur) 447 pp.

Donoso Rodríguez, Andrés (2004): "Comentarios al fallo de la Corte Suprema sobre la tuición de las menores López Atala”, Revista de Derecho de la Universidad Finis Terrae $\mathrm{N}^{\circ}$ 8: pp. 207-243.

EekelaAR, John (2006): Family Law and Personal Life (Londres, Oxford University Press) $195 \mathrm{pp}$.

ELSTER, Jon (1987), "Solomonic Judgements: Against the Best Interest of the Child", The University of Chicago Law Review No 54: pp. 1-45.

Gill, Bruce D. (2001): "Best Interest of the Child? A Critique of Judicially Sanctioned Arguments Denying Child Custody to Gays and Lesbians", Tennesee Law Review, vol. 68: pp. 361-393.

Glendon, Mary Ann (1986): "Fixed Rules and Discretion in Contemporary Family Law and Succession Law”, Tulane Law Review N 60: pp. 1165-1197.

Goldstein, Joseph, Solnit, Albert J., Goldstein, Sonja, y Freud, Anna (1996): The Best Interests of the Child. The Least Detrimental Alternative (New York, The Free Press) $325 \mathrm{pp}$.

GÓMEZ DE LA TORRE, Maricruz (2000): "El interés superior del niño”, Gaceta Jurídica $\mathrm{N}^{\circ}$ 238: pp. 23-26.

GÓMEZ DE LA TORRE, Maricruz (2007): El sistema filiativo chileno (Santiago, Editorial Jurídica de Chile) 379 pp.

GORRIGA GORINA, Margarita (2008): El criterio de la continuidad frente a la guarda conjunta, en: InDret 3/2008. Disponible en: http://www.indret.com/pdf/562_es.pdf [fecha de consulta: 13 de octubre de 2009].

Houlgate, Laurence D. (2005): Children's Rights, State Intervention, Custody and Divorce: Contradictions in Ethics and Family Law (New York, The Edwin Mellen Press,) p. 243. 
Lathrop Gómez, Fabiola (2005): Cuidado personal de los hijos (Santiago, PuntoLex) $160 \mathrm{pp}$.

LATHrop GÓMEZ, Fabiola (2008): Custodia compartida de los hijos (Madrid, La Ley) $582 \mathrm{pp}$.

LinACERO de la Fuente, María (2006): "Leyes de Familia y Constitución: Ley 13/2005, de 1 de julio y Ley 15/2005, de 8 de julio", Revista de Derecho Privado (Madrid) pp. 33-82.

MACCOBy, Eleanor E. y MnOokin, Robert H. (1992): Dividing the Child. Social and Legal Dilemmas of Custody (Cambridge, Harvard University Press) 369 pp.

Mason, Mary Ann (1994): From Father's Property to Children's Rights: The History of Child Custody in the United States (New York, Columbia University Press) 237 pp.

Mason, Mary Ann (1999): The Custody Wars (New York, Basic Books) 278 pp.

MnOokin, Robert (1975): "Child-Custody Adjudications: Judicial Functions in the Face of Indeterminacy”, Law \& Contemporary Problems $N^{\circ} 39$ : pp. 226-293.

Navarro Beltrán, Enrique (2004): "Un caso de tuición a la luz del Derecho Constitucional”, Revista de Derecho Público Nº6: pp. 427 y 428.

PARKINSON, Patrick (2007): "Family Law and the Indissolubility of Parenthood", Family Law Quarterly No 40: pp. 237-280.

Pereira ANABAlÓN, Hugo (1954): La cosa juzgada formal en el procedimiento civil chileno (Santiago, Editorial Jurídica de Chile) 222 pp.

Rivera Álvarez, Joaquín María (2005): "La custodia compartida: génesis del nuevo artículo 92 del Código Civil”, Cuadernos de Trabajo Social, vol. 18: pp. 137-162.

Rivero HernándeZ, Francisco (2007): El interés del menor (Madrid, Dykinson) 329 pp. Rodríguez PinTO, María Sara (1999): "El derecho a mantener una relación directa y regular con el hijo (ex derecho de visitas)", Gaceta Jurídica No 232: pp. 27-38.

Rodríguez Pinto, María Sara (2008): "La tuición compartida o alternada en Chile. Conflictos entre el interés superior del niño y los intereses de padres separados", Estudios de Derecho Civil IV (en prensa)

Rogel VIDE, Carlos (2005): "En torno a la custodia compartida de los hijos de padres separados", Revista General de Legislación y Jurisprudencia N 1: pp. 73-96.

Romero SEguel, Alejandro (2002): La cosa juzgada en el proceso civil chileno (Santiago, Editorial Jurídica de Chile) 157 pp.

ROZAS Vial, Fernando (1990): Análisis de las reformas que introdujo la Ley $N^{\circ} 18.802$ (Santiago, Editorial Jurídica de Chile) 73 pp.

Ruiz-Tagle Vial, Pablo (2004): "El mismo caso de tuición a la luz de otro Derecho Constitucional”, Revista de Derecho Público No 66: pp. 429-432.

SCALA, Jorge (2005): “Corte Suprema, 31 de mayo de 2004. Tuición definitiva de menores", Ius Publicum No 15: pp. 247-258.

SChePARD, Andrew I. (2004): Children, Courts and Custody. Interdisciplinary Models for Divorcing Families (New York, Cambridge University Press) 224 pp.

SCHMidT HOTT, Claudia (2004): "De las relaciones parentales conforme al nuevo estatuto filiativo", en: SCHMIDT HотT, Claudia et al. (dir.), Instituciones de Derecho de Familia (Santiago, LexisNexis) pp. 35-144. 
SCHMidT, Claudia y Veloso, Paulina (2001): La filiación en el nuevo Derecho de familia (Santiago, ConoSur) p. 453.

SCOTT, Elizabeth S. (2002): “Divorce, Children's Welfare and the Culture Wars”, Virginia Journal of Social Policy and the Law, vol. 9: pp. 95-115.

Shapiro, Julie (1996): "Custody and Conduct: How the Law Fails Lesbian and Gay Parents and Their Children”, Indiana Law Journal, vol. 71: pp. 623-671.

Somarriva Undurraga, Manuel (1983a): Derecho de Familia (Santiago, Ediar Editores) $743 \mathrm{pp}$.

Somarriva Undurraga, Manuel (1983b): Evolución del Código Civil chileno (Bogotá, Temis).

Toledo VÁsquez, Patsilí (2005): “Derechos humanos y tuición”, Anuario de Derechos Humanos 2005: pp. 145-148.

Turner SAElzer, Susan (2004): "Sentencia sobre determinación de la titularidad del cuidado personal de los hijos menores". Comentario a May con Cabral, Corte de Apelaciones de Santiago, 1 de septiembre de 2004, Revista de Derecho (Valdivia), vol. XVII: pp. 273-278.

Vial De Amesti, Catalina (2007): Tuición y homosexualidad. El caso López con Atala. (Memoria para optar al grado de licenciada en Derecho, Pontificia Universidad Católica de Chile, dirigida por el profesor Jorge Baraona) $91 \mathrm{pp}$.

Wallerstein, Judith (2000): The Unexpected Legacy of Divorce (New York, Hyperion) 347 pp.

Wallerstein, Judith S. y Blakeslee, Sandra (1996): Second Chances. Men, Women and Children a Decade after Divorce (New York, Houghton Mifflin Company, $3^{\text {rd }}$ rev. ed.) 329 pp.

WARDEL, Lynn D. (1997): "The Potential Impact of Homosexual Parenting on Children", University of Illinois Law Review, vol. 1997 N³: pp. 833-920.

Whitehead, Barbara Dafoe (1997): The Divorce Culture (New York, Alfred A. Knopf) $224 \mathrm{pp}$.

Wilson, James Q. (2002): The Marriage Problem: How Our Culture Has Weakened Families (New York, Harper Collins) 274 pp.

\section{JURISPRUDENCIA CITADA (POR ORDEN ALFABÉTICO DE PARTES)}

C/ Carmen Mondaca Romero (1998): Corte de Apelaciones de Valparaíso, 3 de junio de 1998 (restitución de menor denegada), Gaceta Jurídica N²16, p. 80.

Cazenave con Suazo (2004): Corte Suprema, 19 de abril de 2004. Demanda de entrega inmediata, acogida. Reconvencional de atribución judicial del cuidado personal de los menores, desestimada. Corte de Chillán, 26 de noviembre de 2003. Corte Suprema, 19 de abril de 2004 (casación declarada inadmisible), Repertorio electrónico Legal Publishing 30008.

Di Pede con Silva (2008): Corte Suprema 17 de enero de 2008, Repertorio Electrónico Microjuris Rol 5592-06, MJJ16364. 
Duarte con Olivares (1946): Corte Suprema, 23 de mayo de 1946, Revista de Derecho y Jurisprudencia, t. $44,1^{\text {a }}$ parte, secc. $1^{\text {a }}$, pp. 225-234.

Garrido con Lagos (2008): Corte Suprema, 14 de mayo de 2008 (tuición concedida a la madre, dejando sin efecto atribución convencional previa con el padre), Repertorio electrónico Legal Publishing 39041.

Hernández con Sarmiento (2008): Corte Suprema, 29 de julio de 2008 (recurso de casación acogido; cuidado personal de niña de nueve años adjudicado al padre), Repertorio electrónico Legal Publishing 39439.

Lincopil con Gómez (2008): Corte Suprema, 17 de marzo de 2008 (tuición desestimada por inhabilidad del padre; relación directa y regular con la hija suspendida hasta nuevos antecedentes), Repertorio electrónico Legal Publishing 38420.

López con Atala (2004): Corte Suprema, 31 de mayo de 2004 (tuición concedida en recurso de queja), Repertorio electrónico Legal Publishing 30299 (redacción del voto de mayoría a cargo del ministro señor Jorge Rodríguez Ariztía).

López con Juez del Tribunal de Familia de Viña del Mar (2006): Corte Suprema 7 de diciembre de 2006 (recurso de amparo acogido), Repertorio electrónico Legal Publishing 35714.

Molina con Orellana (1997): Corte de Apelaciones Presidente Pedro Aguirre Cerda, 28 de marzo de 1997 (aplicación directa de la Convención de Derechos del Niño para desestimar la demanda del padre que pide ampliación de un régimen de visitas), Revista de Derecho y Jurisprudencia, tomo 94 (1997), sección 2a, p. 34.

Pino con Castro (2007): Corte Suprema, 9 de julio de 2007, Repertorio electrónico Legal Publishing 36773.

Schuffeneger con Bordagaray (1996): Corte Suprema, 6 de abril de 1996, Repertorio electrónico Legal Publishing 13877.

Toledo con Morales y otra (2000): Corte de Apelaciones de Talca, 26 de julio de 2000, Repertorio electrónico Legal Publishing 21966.

Tuición de la menor Kassandra Arriola Donoso (2008): Corte Suprema, 15 de julio de 2008 (desestima recurso de casación deducido contra sentencia de la Corte de Valparaíso que revoca la de primer grado, rechazando pretensión de progenitores que piden que se les adjudique cuidado personal de su hija contra abuela paterna), Repertorio electrónico Legal Publishing 39469.

Tuición de los menores Ramos Astudillo (1996): Corte de Apelaciones de Antofagasta, 27 de marzo de 1996 (tuición denegada), Gaceta Jurídica N²193, p. 156.

Tuición de Maribel del Carmen Oróstica (1996): Corte de Apelaciones de Valparaíso, 26 junio 1996 (aplicación directa de la Convención de Derechos del Niño para desestimar una demanda de tuición), Revista de Derecho y Jurisprudencia, tomo 93 (1996), II, sección $2^{\mathrm{a}}$, p. 90.

Tuición del menor Benjamin Cabral May (2004): Corte de Apelaciones de Santiago, 1 de septiembre de 2004, Rol 4105-2004 (no publicada).

Tuición del menor Vicente Ibáñez Guzmán (1989): Corte de Apelaciones de Santiago, 30 de mayo de 1989 (invoca el principio del interés del niño para negar tuición a la madre natural), Revista de Derecho y Jurisprudencia, tomo 86 (1989), II, sección 2a , p. 44. 
Zuloaga con Escobar (2002): Corte Suprema, 24 de enero de 2002 (restitución inmediata internacional denegada por aplicación directa del interés superior del niño), Fallos del Mes No 497, p. 339.

\section{NORMAS LEGALES CITADAS}

Constitución Política de la República

Convención de Derechos del Niño

Código Civil

Ley $\mathrm{N}^{\circ}$ 16.618, de Menores. Diario Oficial, 8 de marzo de 1967.

Ley $\mathrm{N}^{\circ}$ 19.585, sobre Filiación Única. Diario Oficial, 26 de octubre de 1998.

Ley N ${ }^{\circ}$ 19.968, Crea los Tribunales de Familia. Diario Oficial, 30 de agosto de 2004.

Ley $N^{\circ}$ 19.947, Establece nueva Ley de Matrimonio Civil. Diario Oficial, 17 de mayo de 2004.

Ley No 4.808, sobre Registro Civil, Diario Oficial, 10 de febrero de 1930 (Texto refundido en Decreto con Fuerza de Ley 1 del Ministerio de Justicia, Diario Oficial, 30 de mayo de 2000).

Diario de Sesiones del Senado, Sesión 12a Ordinaria de 22 de julio de 1998 (Anexo de documentos) p. 1532. 